\title{
Falkner-Skan Equation with Heat Transfer: A New Stochastic Numerical Approach
}

\author{
Imran Khan, ${ }^{1}$ Hakeem Ullah $\mathbb{D}^{1}{ }^{1}$ Hussain AlSalman $\left(\mathbb{D},{ }^{2}\right.$ Mehreen Fiza, ${ }^{1}$ Saeed Islam, \\ Asif Zahoor Raja, ${ }^{3}$ Mohammad Shoaib, ${ }^{4}$ and Abdu H. Gumaei ${ }^{5}{ }^{5}$ \\ ${ }^{1}$ Department of Mathematics, Abdul Wali Khan University, Mardan 23200, Khyber Pakhtunkhwa (K.P), Pakistan \\ ${ }^{2}$ Department of Computer Science, College of Computer and Information Sciences, King Saud University, \\ Riyadh 11543, Saudi Arabia \\ ${ }^{3}$ Future Technology Research Center, National Yunlin University of Science and Technology, 123 University Road, Section 3, \\ Douliou, Yunlin 64002, Taiwan \\ ${ }^{4}$ Department of Mathematics, COMSATS University Islamabad, Attock Campus, Attock 43600, Pakistan \\ ${ }^{5}$ Department of Computer Science, Faculty of Applied Sciences, Taiz University, Taiz 6803, Yemen
}

Correspondence should be addressed to Hakeem Ullah; hakeemullah1@gmail.com,Hussain AlSalman; halsalman@ksu.edu.sa, and Abdu H. Gumaei; abdugumaei@gmail.com

Received 6 June 2021; Revised 10 July 2021; Accepted 2 August 2021; Published 30 August 2021

Academic Editor: Mohammad Yaghoub Abdollahzadeh Jamalabadi

Copyright (c) 2021 Imran Khan et al. This is an open access article distributed under the Creative Commons Attribution License, which permits unrestricted use, distribution, and reproduction in any medium, provided the original work is properly cited.

\begin{abstract}
In this study, a new computing model is developed using the strength of feedforward neural networks with the Levenberg-Marquardt method- (NN-BLMM-) based backpropagation technique. It is used to find a solution for the nonlinear system obtained from the governing equations of Falkner-Skan with heat transfer (FSE-HT). Moreover, the partial differential equations (PDEs) for the unsteady squeezing flow of heat and mass transfer of the viscous fluid are converted into ordinary differential equations (ODEs) with the help of similarity transformation. A dataset for the proposed NN-BLMM-based model is generated in different scenarios by a variation of various embedding parameters, Deborah number $(\beta)$ and Prandtl number (Pr). The training (TR), testing (TS), and validation (VD) of the NN-BLMM model are evaluated in the generated scenarios to compare the obtained results with the reference results. For the fluidic system convergence analysis, a number of metrics such as the mean square error (MSE), error histogram (EH), and regression $(\mathrm{RG})$ plots are utilized for measuring the effectiveness and performance of the NN-BLMM infrastructure model. The experiments showed that comparisons between the results of the proposed model and the reference results match in terms of convergence up to E-05 to E-10. This proves the validity of the NN-BLMM model. Furthermore, the results demonstrated that there is an increase in the velocity profile and a decrease in the thickness of the thermal boundary layer by increasing the Deborah number. Also, the thickness of the thermal boundary layer is decreased by increasing the Prandtl number.
\end{abstract}

\section{Introduction}

The boundary layer flow of an incompressible liquid through a stretching sheet is commonly used in many industrial and engineering processes. The field has been attracting researchers in the past few years. The boundary layer flow has major applications in industries such as aerodynamic extraction of polymer paper from debris, thermal wrapping, cooling plate with no cooling tuber, boundary layer next to the liquid film in the condensation phase, and glass fiber development [1-3]. By immersing them in quiescent liquids, many metal processes need to cool continuous fibers. The mechanical features of the final product depend only on the drawing costs and the process temperature. Sakiadis $[4,5]$ experimented with new work in this area, and many researchers in the field have investigated the flow of the boundary layer into the ongoing stretching sheet at an increasing speed. A closed-form solution for the viscous flow of an incompressible fluid was obtained by Crane [6]. Gupta and Gupta [7] studied the same effects as given in [6] by 


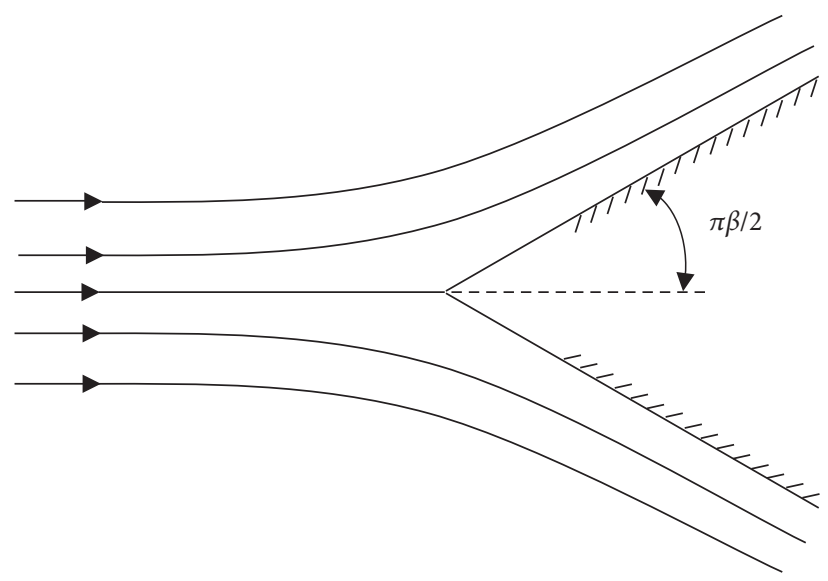

Figure 1: The geometry of the problem.

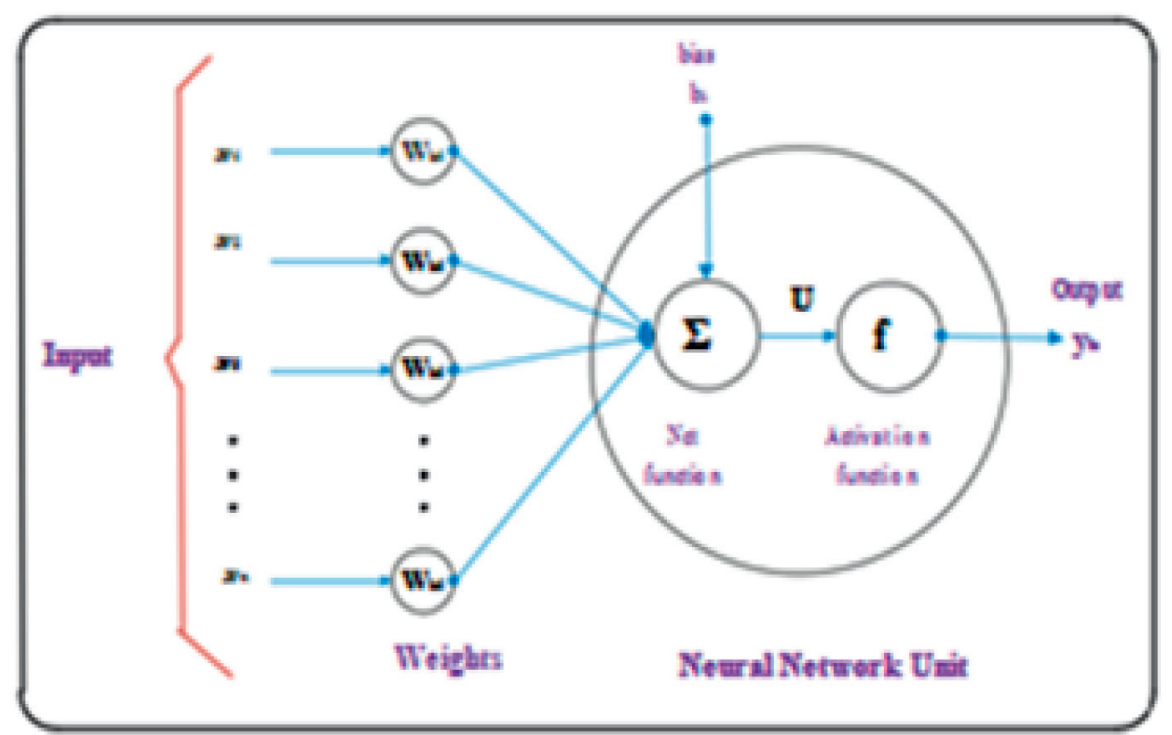

Figure 2: The structure of a single neural network model.

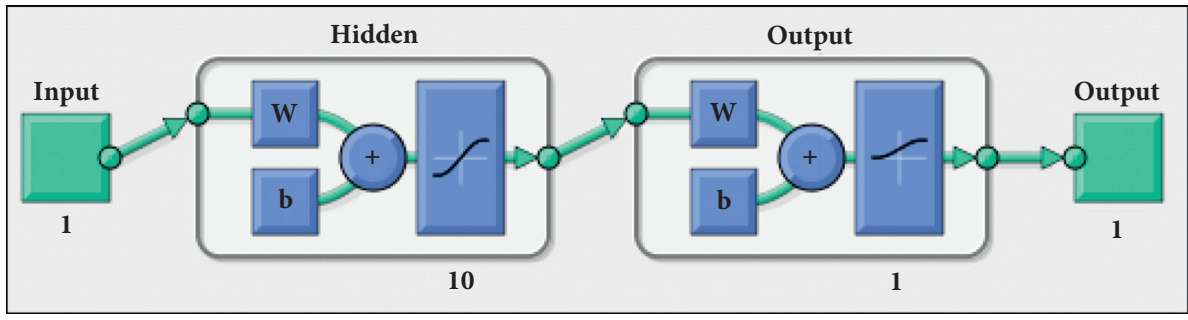

Figure 3: Graphical representation of NN-BLMM input, hidden, and output layers.

TABLE 1: Defining the physical parameters of interest for the scenarios and cases of FSE-HT.

\begin{tabular}{|c|c|c|c|}
\hline \multirow{2}{*}{ Scenarios } & \multirow{2}{*}{ Cases } & \multicolumn{2}{|c|}{ Physical quantity } \\
\hline & & $\beta$ & $\operatorname{Pr}$ \\
\hline \multirow{3}{*}{1} & 1 & 2 & 0.5 \\
\hline & 2 & 4 & 0.5 \\
\hline & 3 & 6 & 0.5 \\
\hline \multirow{3}{*}{2} & 1 & 4 & 0.5 \\
\hline & 2 & 4 & 1.0 \\
\hline & 3 & 4 & 1.5 \\
\hline
\end{tabular}




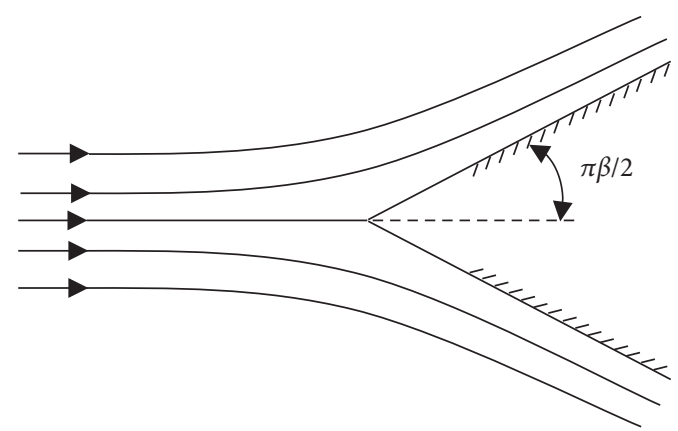

(a) $f^{\prime \prime \prime}(\xi)+f(\xi) f^{\prime \prime}(\xi)+\beta\left(1-\left(f^{\prime}(\xi)\right)^{2}\right)=0$,

$\theta^{\prime \prime}(\xi)+\operatorname{Pr} f(\xi) \theta^{\prime}(\xi)=0$,

$f(0)=0, f^{\prime}(0)=0, f^{\prime}(\infty)=1$,

$\theta(0)=1, \theta(\infty)=0$.

(b)

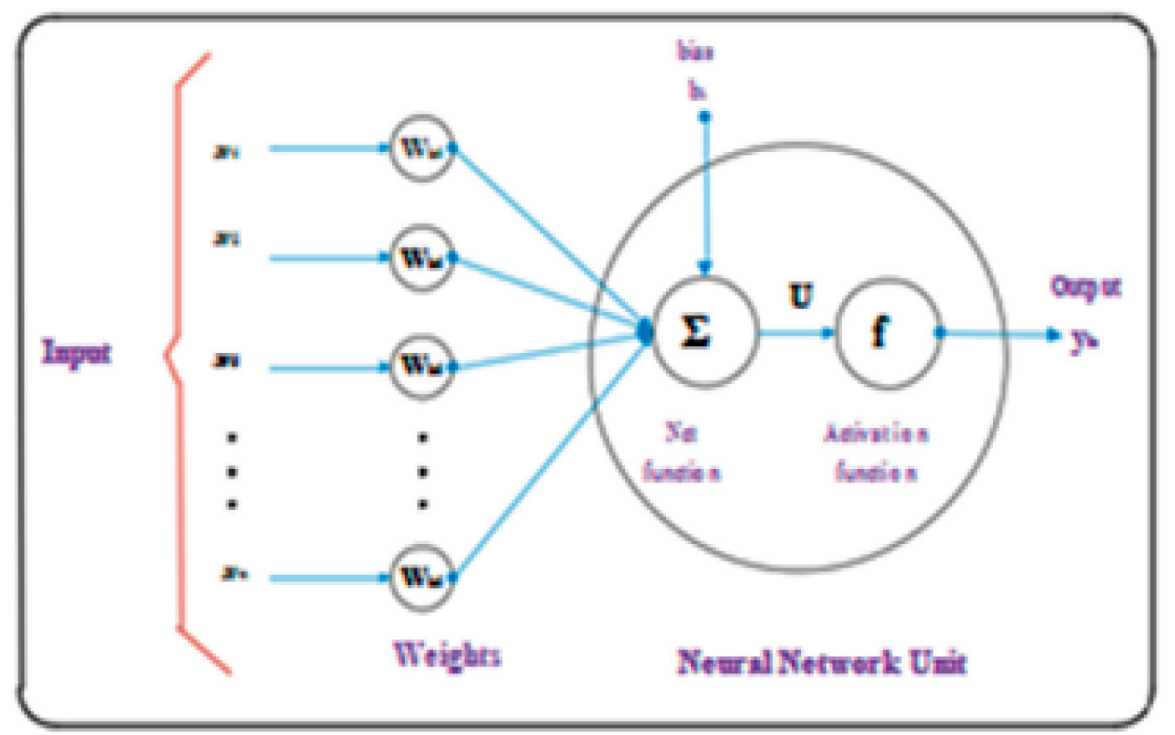

(c)

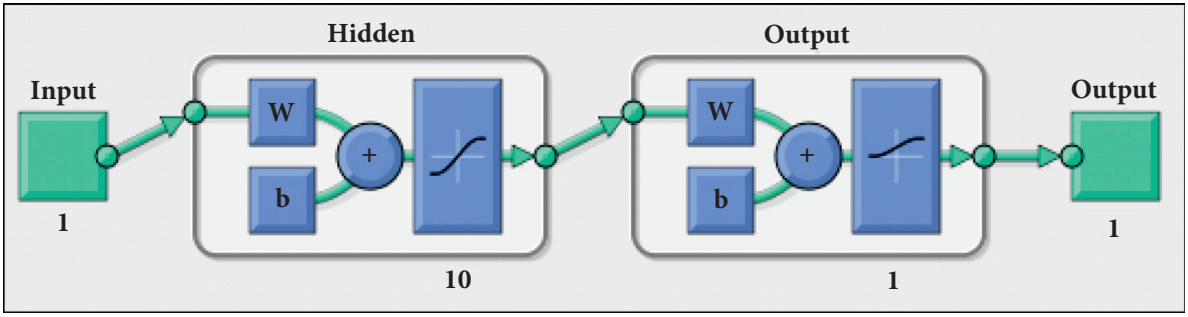

(d)

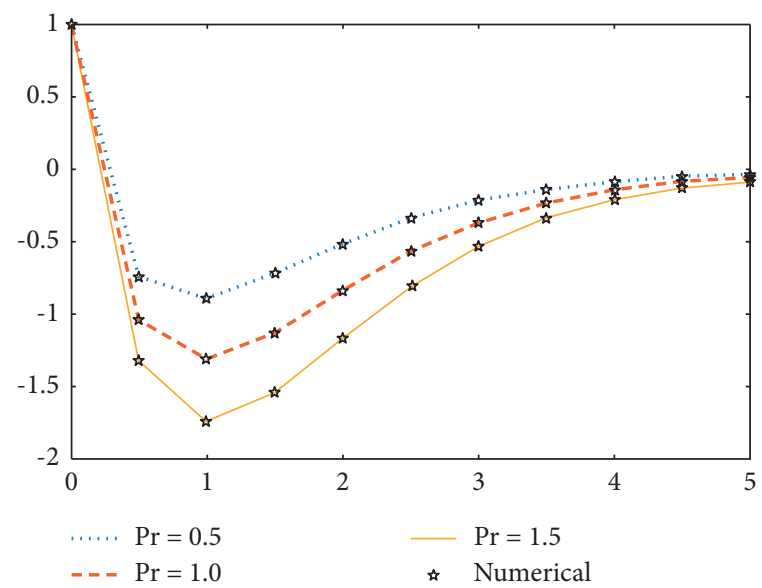

Analysis of assessment

i. Mean square error based fitness

ii. Absolute error analysis

iii. State transition analysis

iv. Error histograms

v. Regression studies

(e)

(f)

Figure 4: The workflow of the proposed NN-BLMM for processing the FSE-HT. (a) The geometry of the problem. (b) Formulation of the problem. (c) Intelligent computing: neuron model integrated to develop the proposed network. (d) Results. (e) Comparative analysis. 


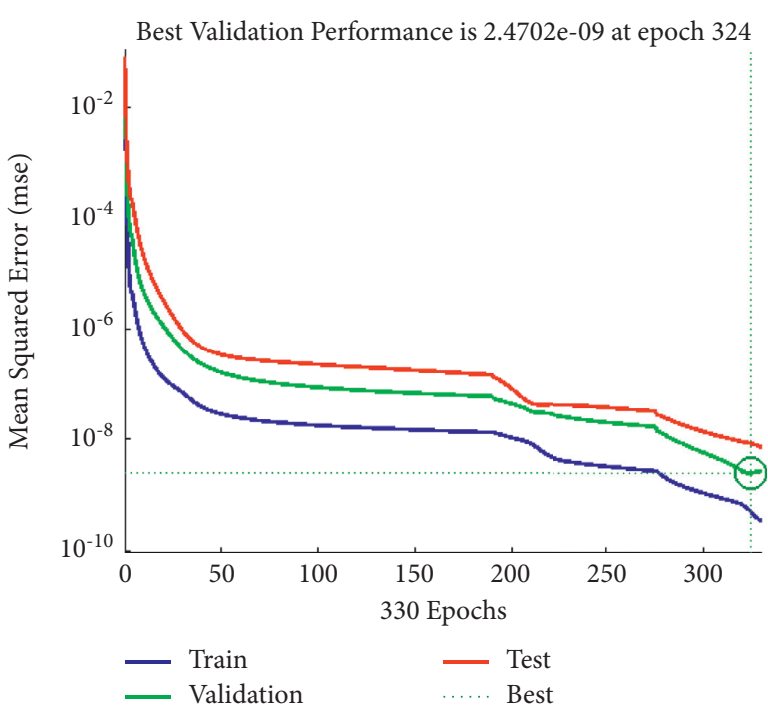

(a)

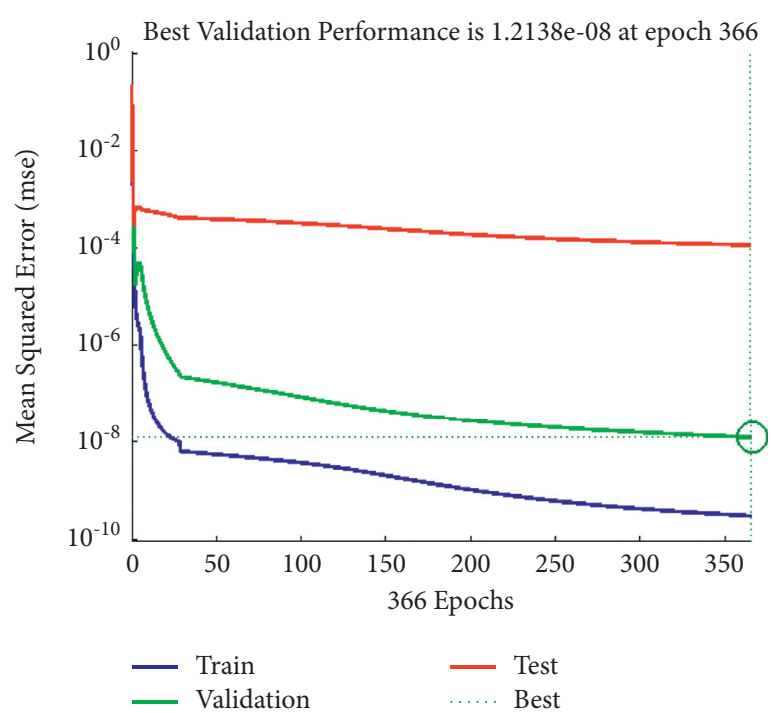

(c)

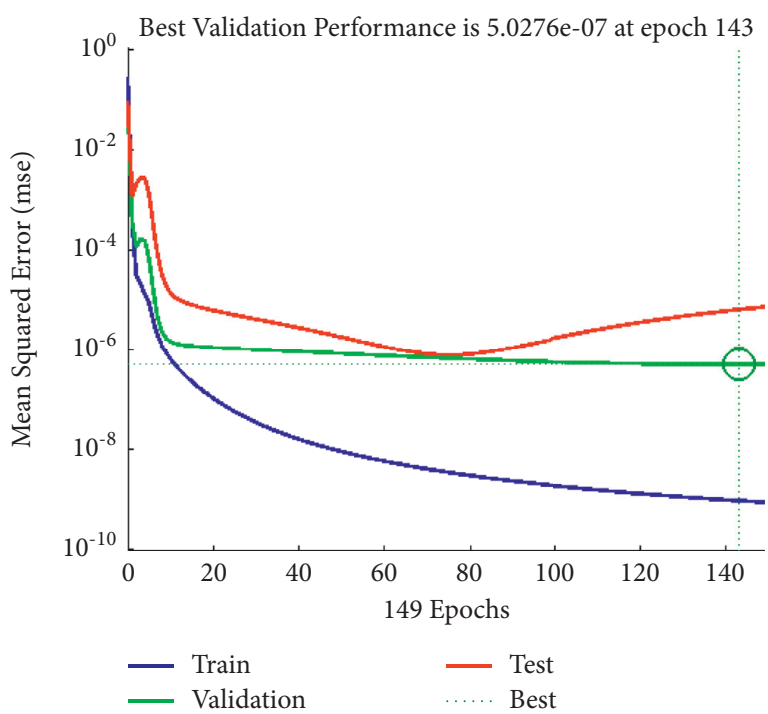

(e)

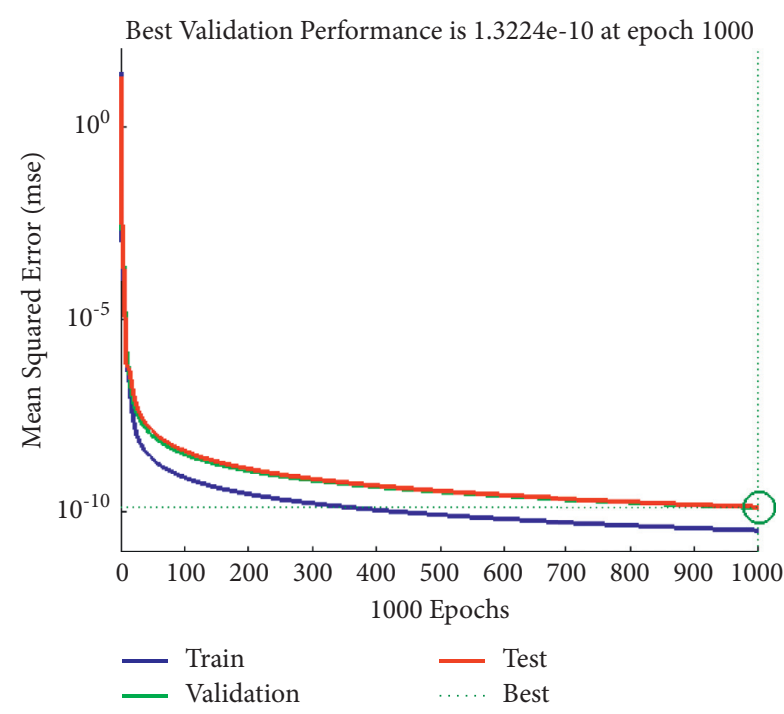

(b)

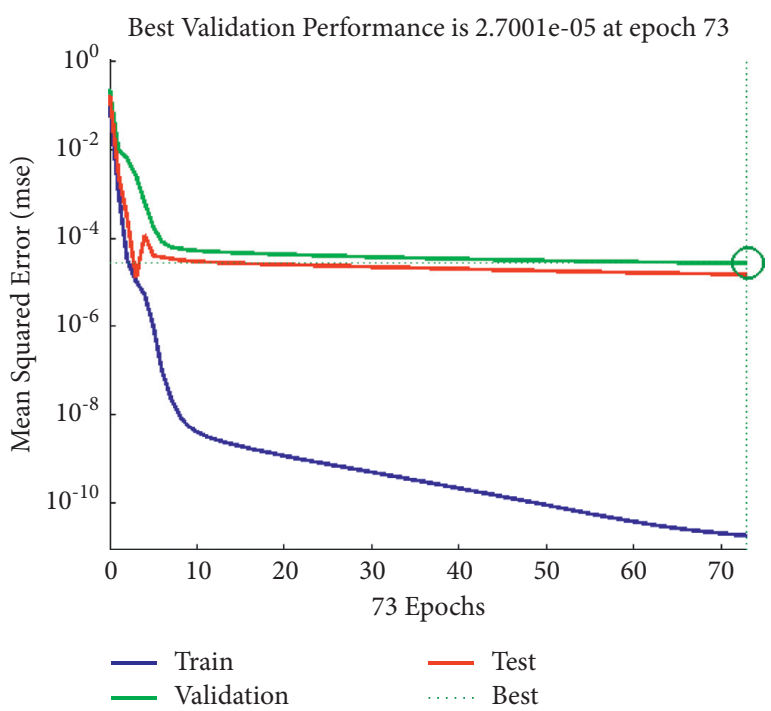

(d)

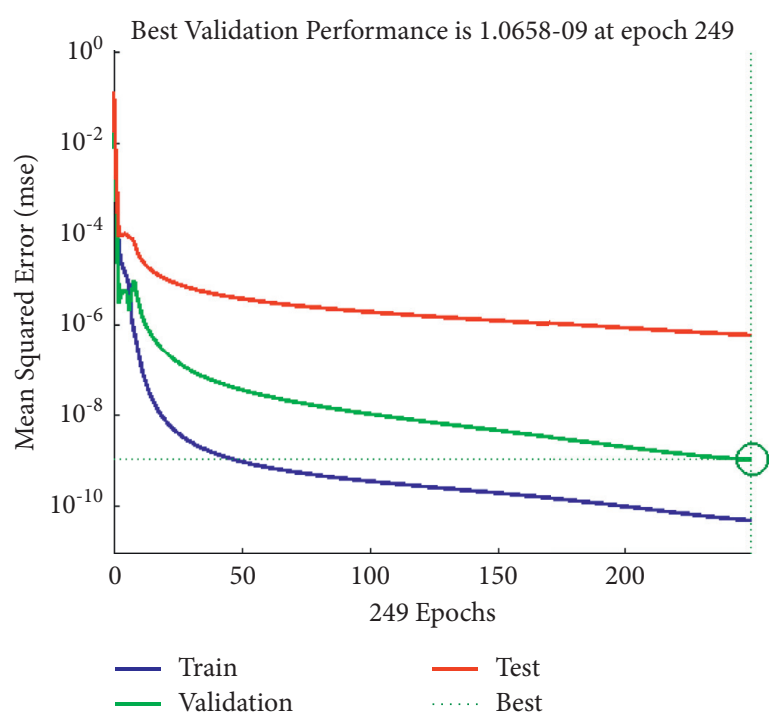

(f)

Figure 5: The MSE results of the proposed NN-BLMM to solve the FSE-HT. (a) The MSE results in case 1 for scenario 1. (b) The MSE results in case 2 for scenario 1. (c) The MSE results in case 3 for scenario 1. (d) The MSE results in case 1 for scenario 2. (e) The MSE results in case 2 for scenario 2. (f) The MSE results in case 3 for scenario 2. 


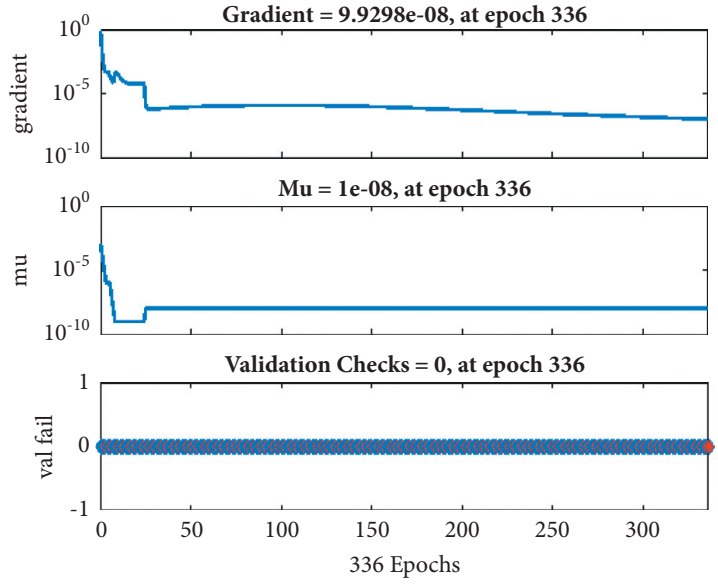

(a)
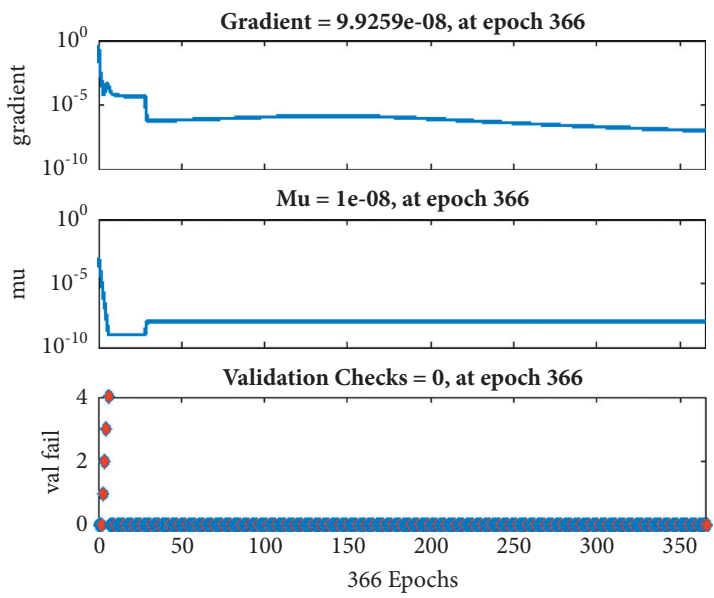

(c)
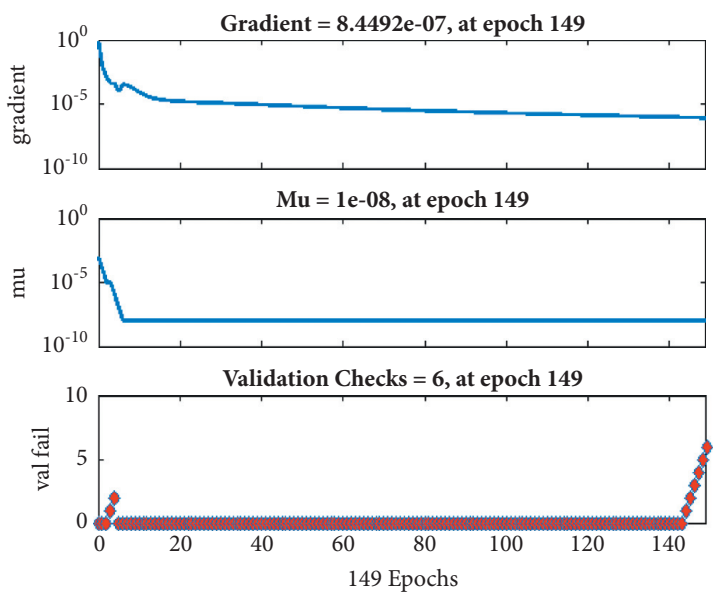

(e)
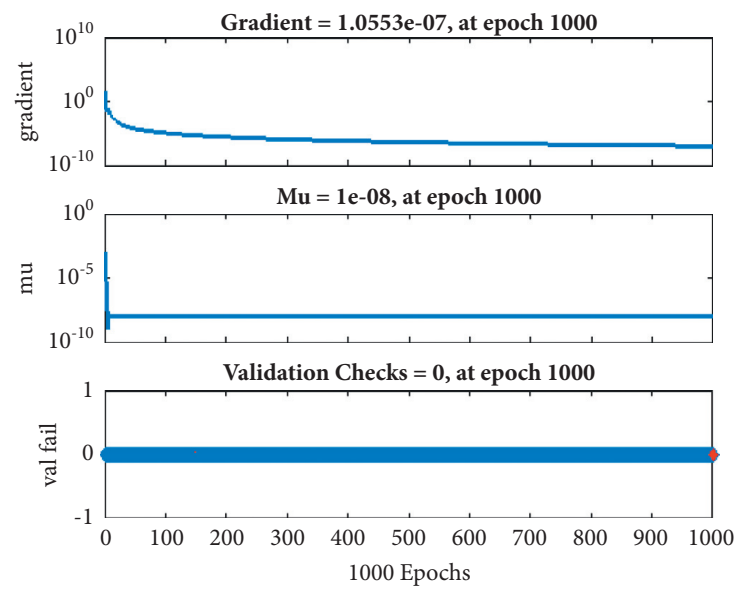

(b)

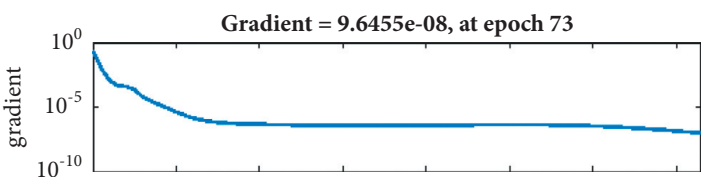

$\mathrm{Mu}=1 \mathrm{e}-08$, at epoch 73
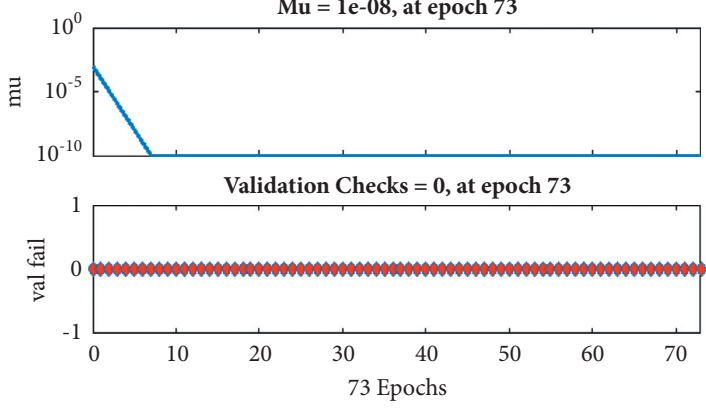

(d)
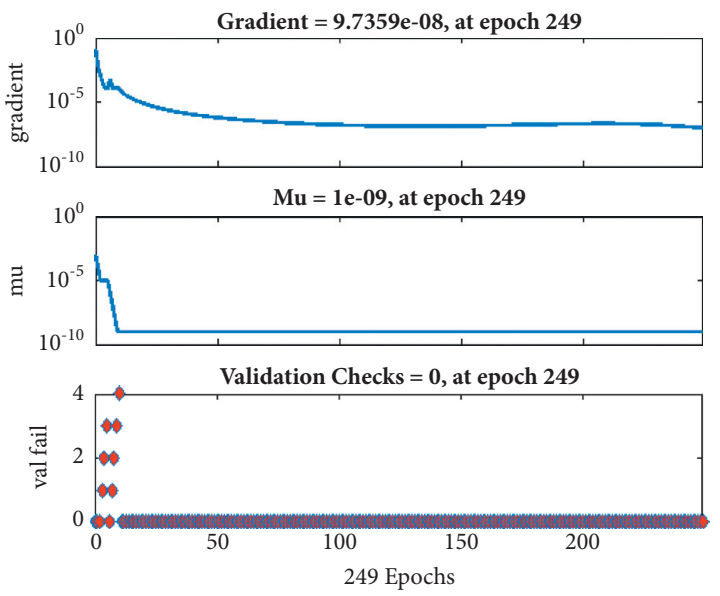

(f)

FIGURE 6: The dynamic results of transition states for the NN-BLMM to solve the FSE-HT. (a) The transition state results in case 1 for scenario 1. (b) The transition state results in case 2 for scenario 1. (c) The transition state results in case 3 for scenario 1. (d) The transition state results in case 1 for scenario 2. (e) The transition state results in case 2 for scenario 2. (f) The transition state results in case 3 for scenario 2.

considering the fluid electrically conducting and porous medium with suction/injection by Anderson [8]. Ariel [9] investigated the combined effect of viscoelasticity and magnetic field on the Crane's problem. Since a stretching sheet can occur in a variety of ways, the flow through the stretching sheet does not always need to be of two sizes. If the extension is radial, it can be three. A flat surface of three stretches and the same width was examined by Wang [10]. Brady and Acrivos [11] monitored the flow inside the channel or tube and the Wang flow outside the performing 

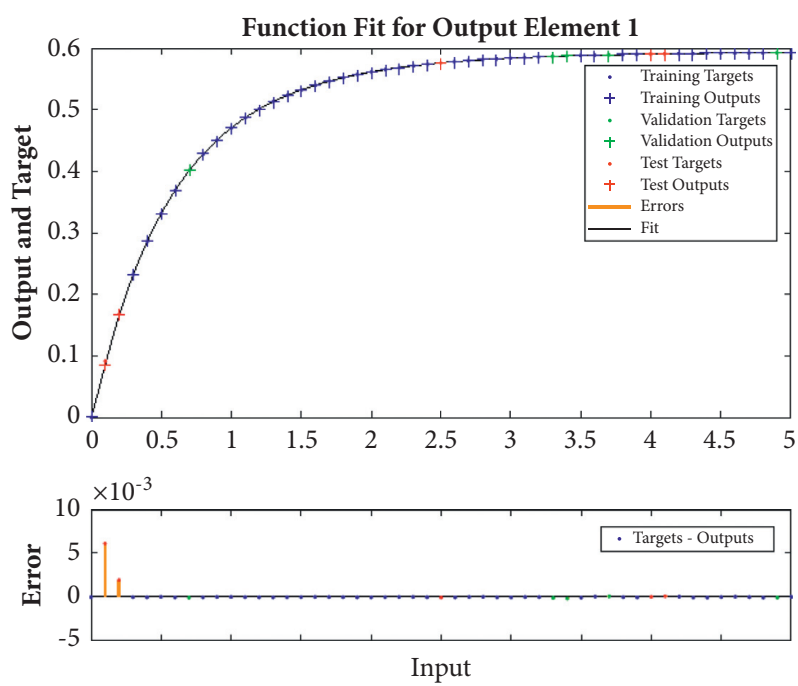

FIgURE 7: The results of the NN-BLMM compared with the reference solution in case 1 of scenario 1 for FSE-HT.
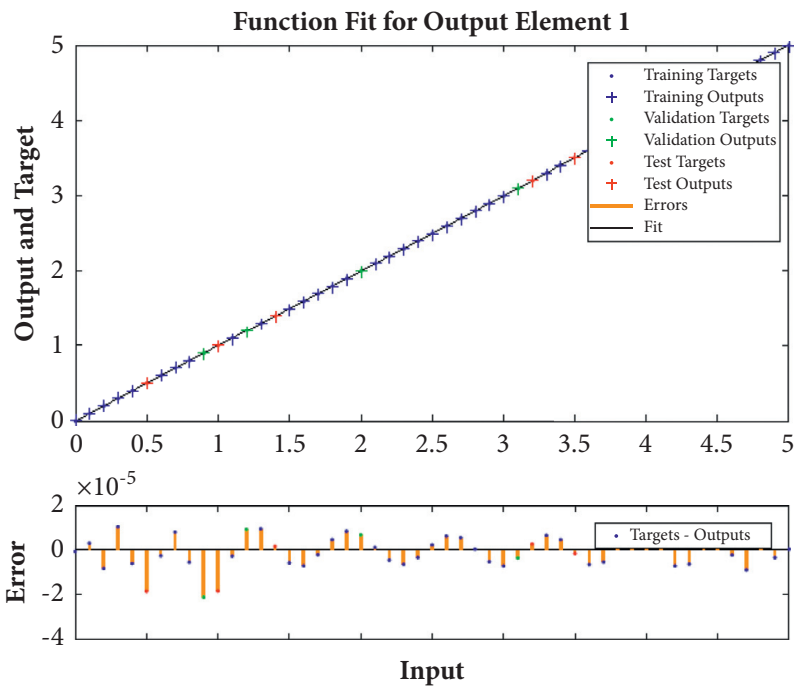

FIGURE 8: The results of the NN-BLMM compared with the reference solution in case 2 of scenario 1 for FSE-HT.
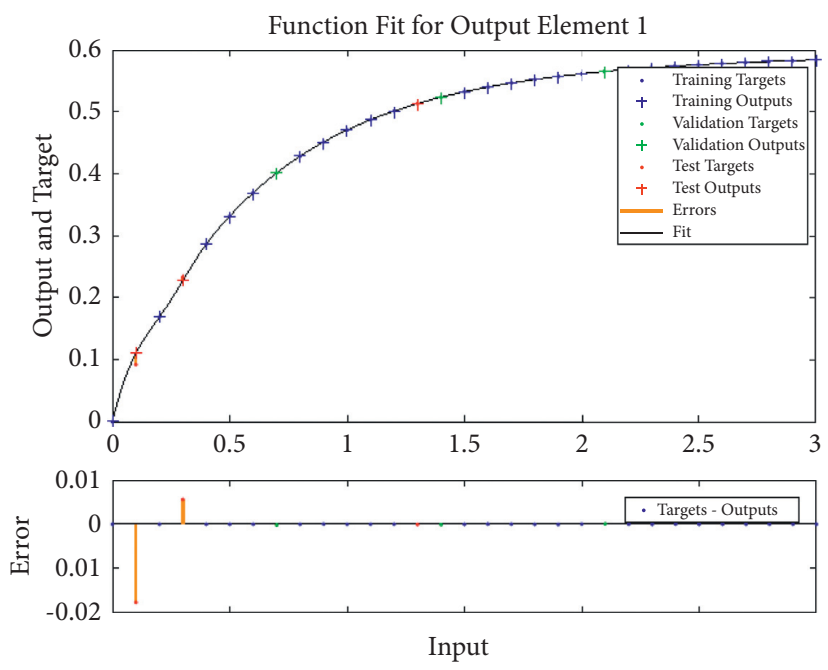

FIGURE 9: The results of the NN-BLMM compared with the reference solution in case 3 of scenario 1 for FSE-HT. 

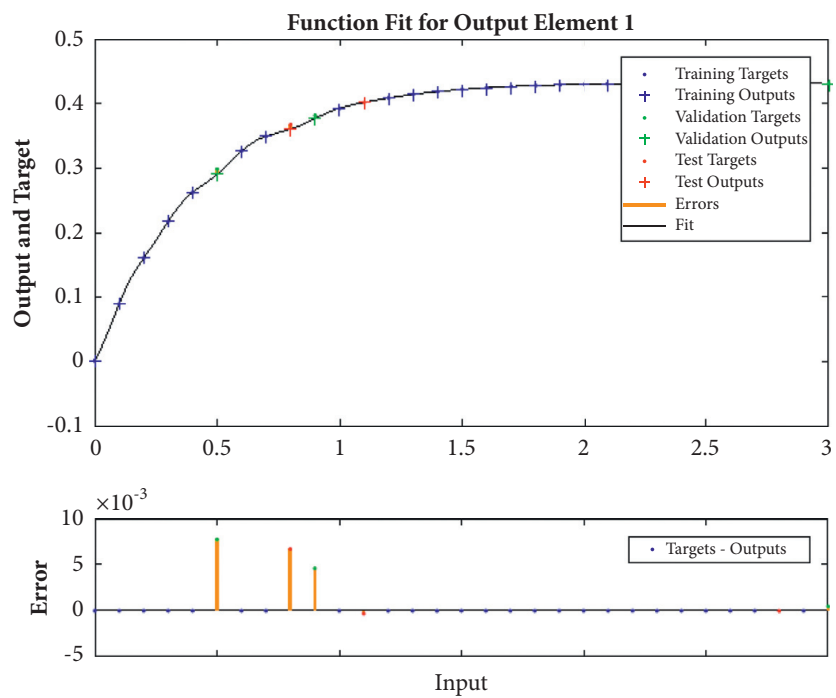

FIgURE 10: The results of the NN-BLMM compared with the reference solution in case 1 of scenario 2 for FSE-HT.
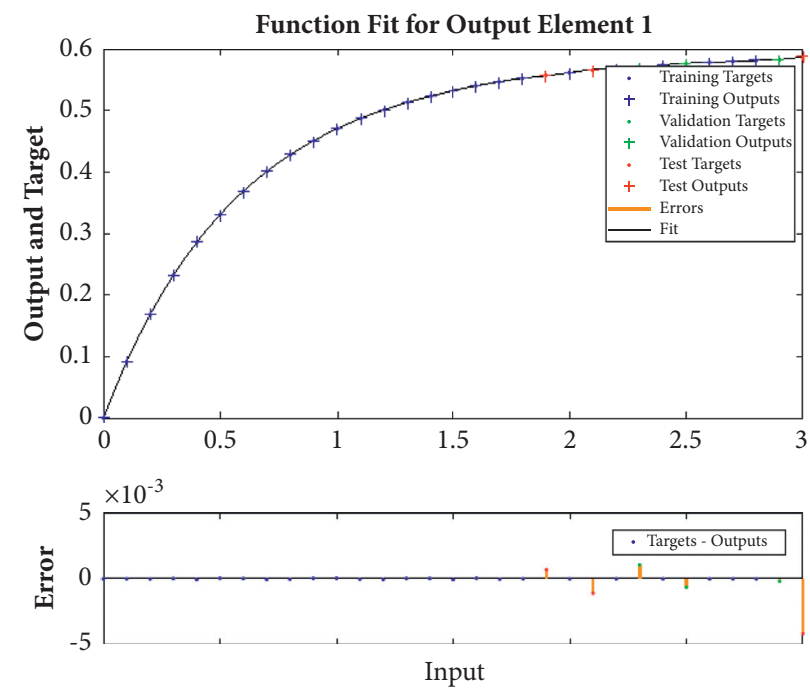

FIgURE 11: The results of the NN-BLMM compared with the reference solution in case 2 of scenario 2 for FSE-HT.
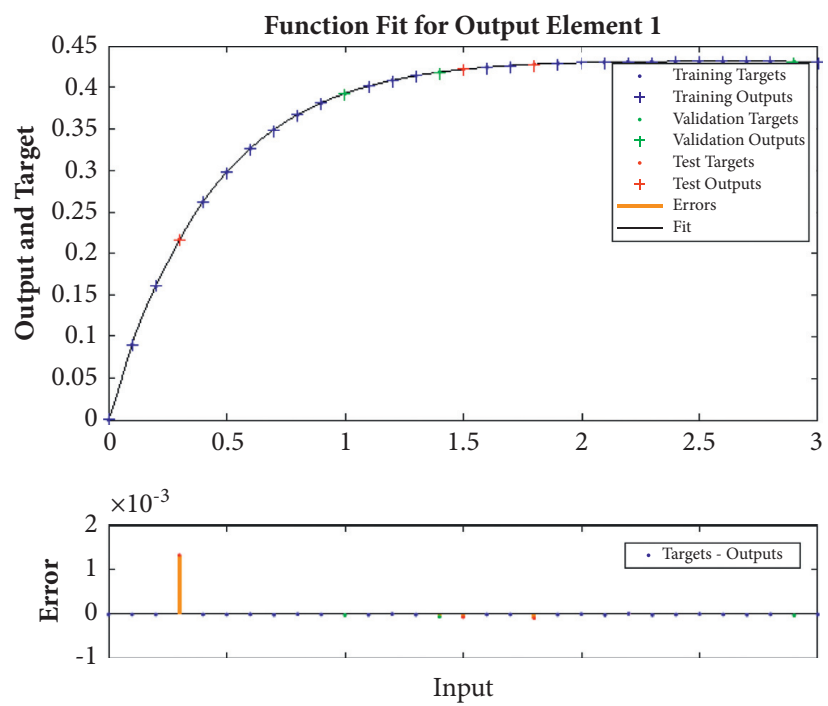

FIgURE 12: The results of the NN-BLMM compared with the reference solution in case 3 of scenario 2 for FSE-HT. 


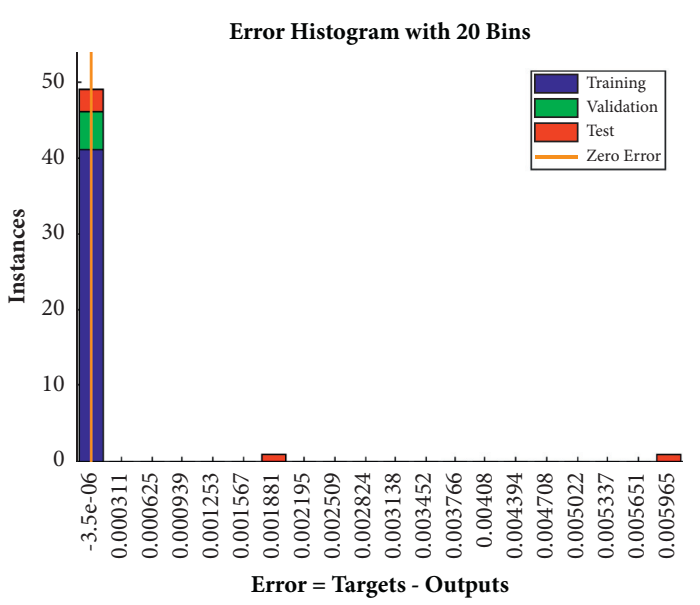

(a)

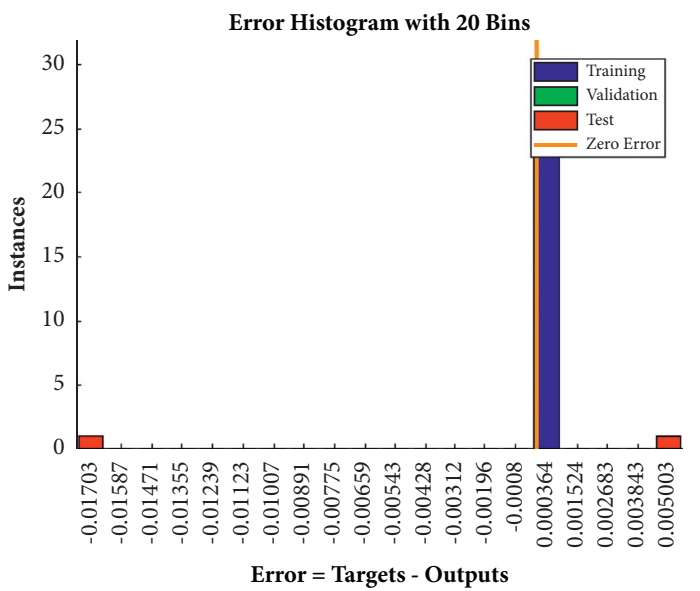

(c)

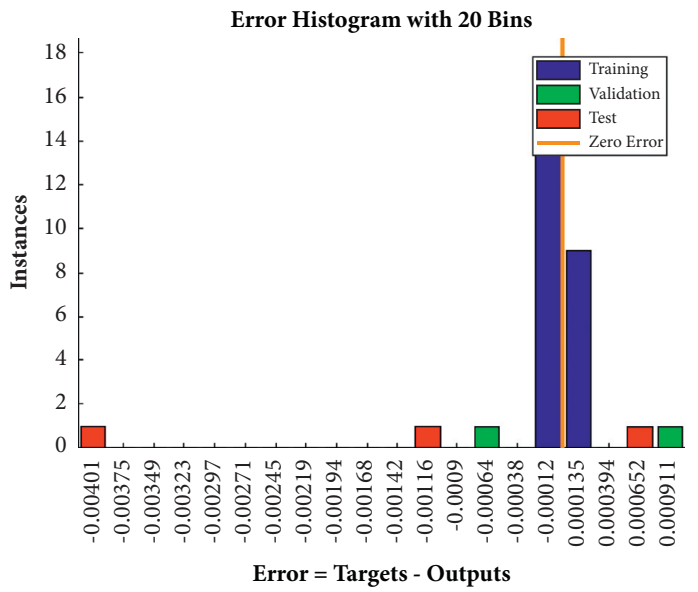

(e)

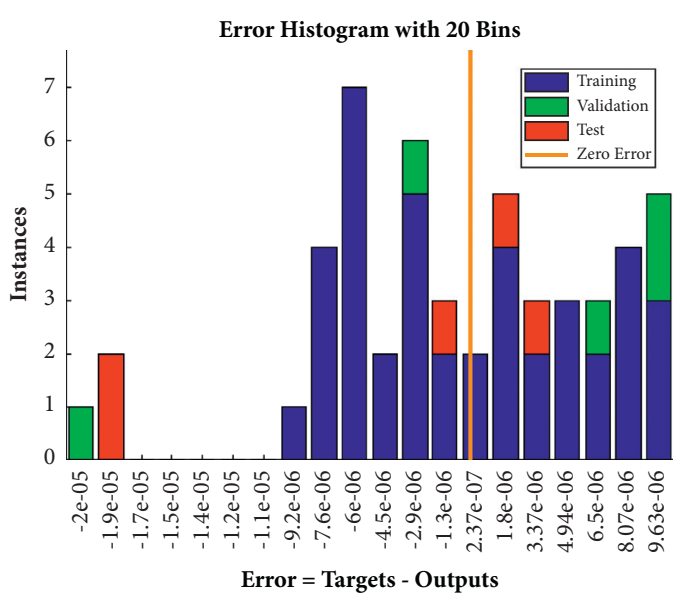

(b)

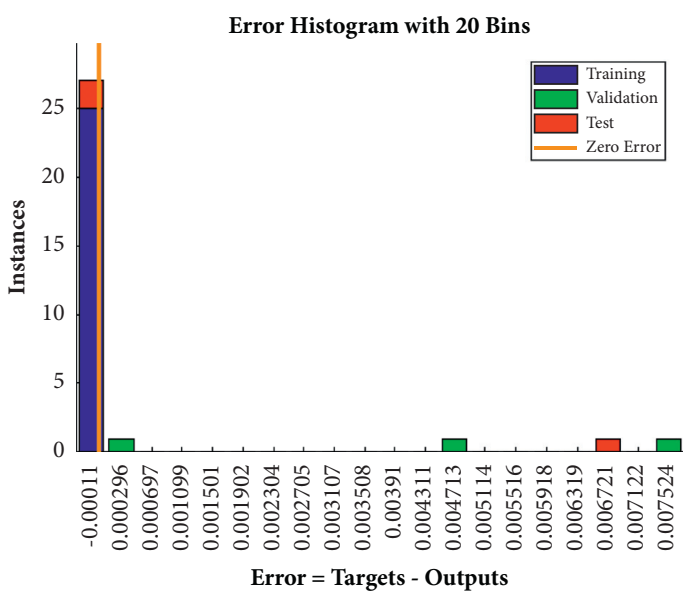

(d)

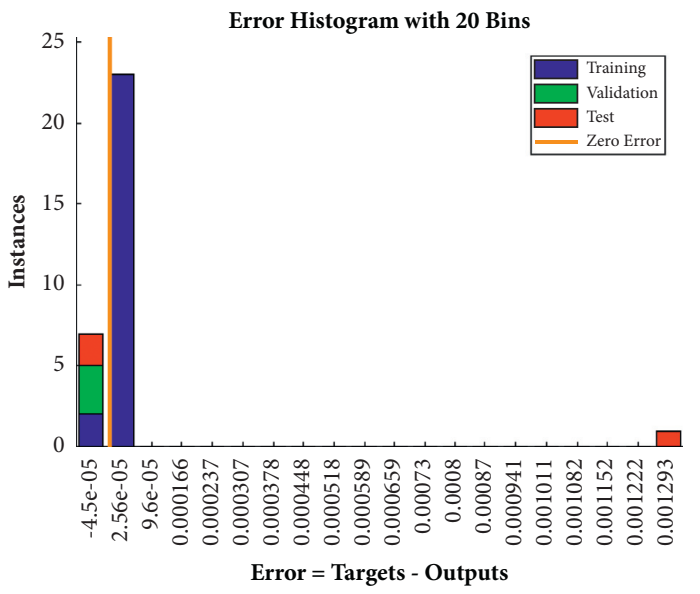

(f)

FIGURE 13: Studying the error histograms for the NN-BLMM results in cases 1-3 of scenarios 1 and 2 for FSE-HT. (a) Error histogram for scenario 1 in case 1. (b) Error histogram for scenario 1 in case 2. (c) Error histogram for scenario 1 in case 3. (d) Error histogram for scenario 2 in case 1. (e) Error histogram for scenario 2 in case 2. (f) Error histogram for scenario 2 in case 3.

tube [12]. Wang [13] and Usha and Sridharan [14] tested the unstable SS. Ariel [15] used HPM and expanded HPM to obtain a solution for analysis in axisymmetric flow across the flat layer. A noniterative solution for MHD flow was provided by Ariel et al. [16]. The problem of a third-order nonlinear two-point boundary value with no exact solutions is commonly known as the Falkner-Skan equation (FSE). Due to the importance of the boundary layer theory, the FSE is considered widely in the last forty years. Due to the nonlinear nature of the FSE having no exact solutions available in the literature, the scientists have tried the analytical and numerical approaches. Hartree [17] obtained a 

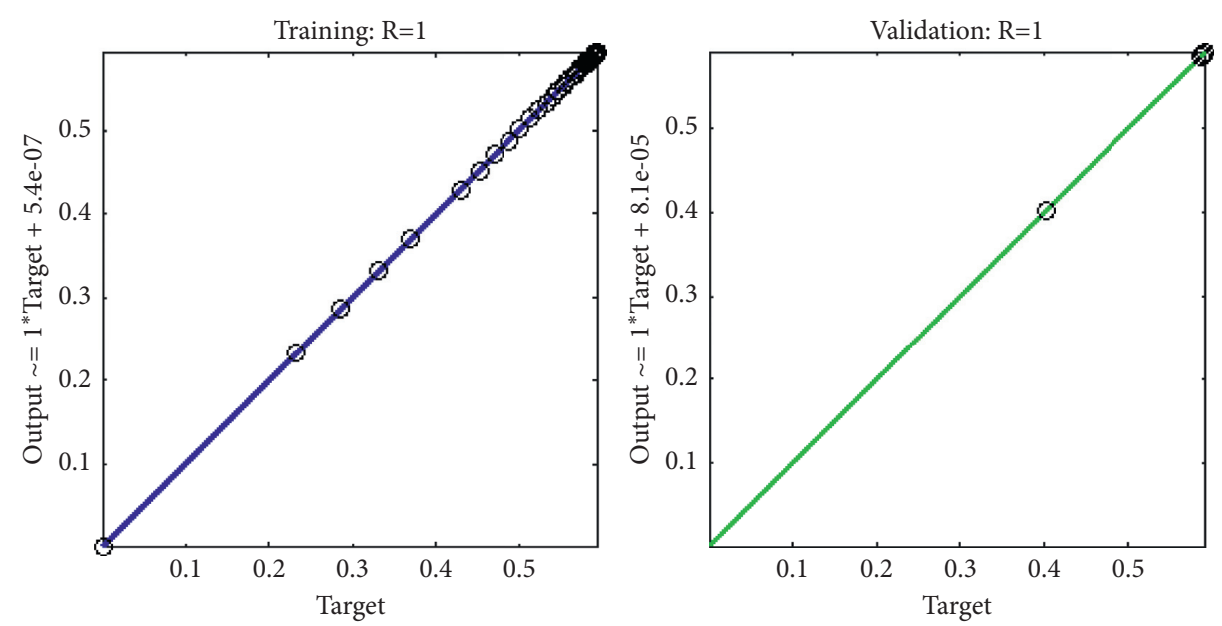

$$
\begin{array}{ll}
\text { Data } \\
\text { - Fit } \\
\ldots \ldots . & \mathrm{Y}=\mathrm{T}
\end{array}
$$

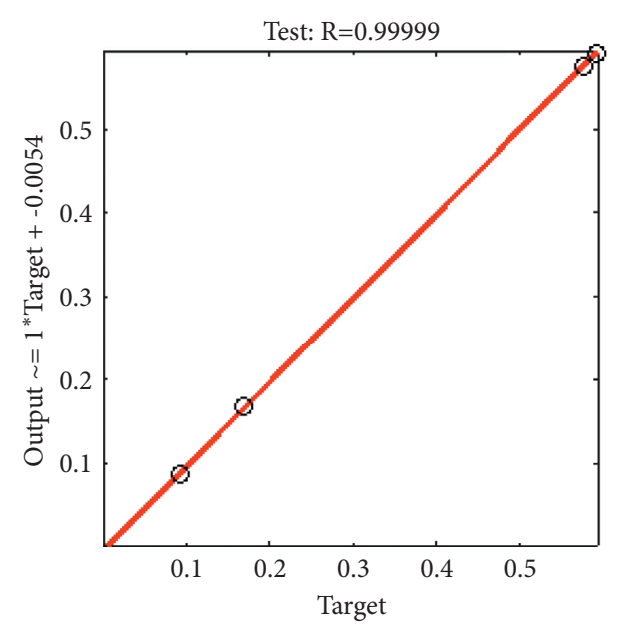

O Data

- Fit

… $\mathrm{Y}=\mathrm{T}$

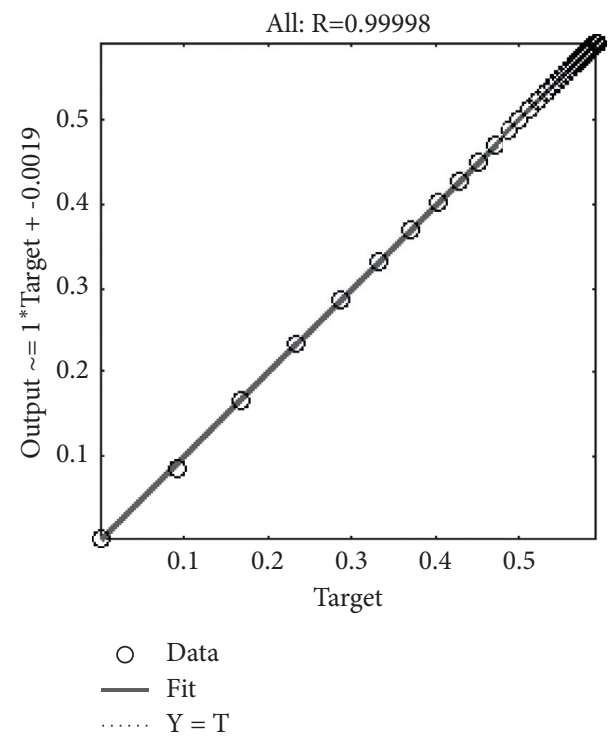

FIgURE 14: Regression illustration of NN-BLMM results in case 1 of scenario 1 for FSE-HT.

solution of the FSE numerically. Smith and Cebeci and Keller $[18,19]$ solved the FSE by the shooting method. Meksyn [20] solved the FSE by analytic approximation. Asaithambi [21-23] found the FSE solution by finite differences, and Salama studied the FSE by solving it with a higher-order method [24]. Zhang and Chen used the iterative method for handling the FSE [25]. Rosales-Vera and Valencia used the Fourier transform for the solution of the FSE [26]. Liao [27] applied the homotopy analysis method (HAM) to solve the FSE recently. Recently, Ullah et al. modified the optimal homotopy asymptotic method (OHAM) for the FSE [28]. The important special case of the FSE is known as the Blasius equation. Rosales and Valencia [29] solved this problem using the Fourier series method. Boyd [30] established the solution of the FSE using the numerical method. In the literature survey, the FSE is solved by analytical and numerical methods. Both these methods have some disadvantages as analytical techniques mostly required the initial guess and small parameter assumption and may affect the result. Also, the numerical methods required linearization and discretization techniques which can affect the accuracy. Therefore, a new stochastic method is proposed to solve the FSE-HT, and the results are compared with the literature validating the method.

The stochastic methods are relatively less used for the solution of the fluid system. The use of stochastic methods can be seen in thermodynamics, astrophysics, offline circuits, atomic physics, MHD, plasma physics, fluid dynamics, electromagnetics, nanotechnology, bioinformatics, electricity, energy, finance, and random matrix theory [31-36]. The stochastic method would be used for important and reputed fluidic models [37-44].

According to the literature survey, no research has applied artificial intelligent techniques through the NN-BLMM to solve the FSE-HT. The purpose of this study is to use the NN-BLMM for the solution of FSE-HT.

The critical aspect of the proposed computing paradigm is given as follows: 

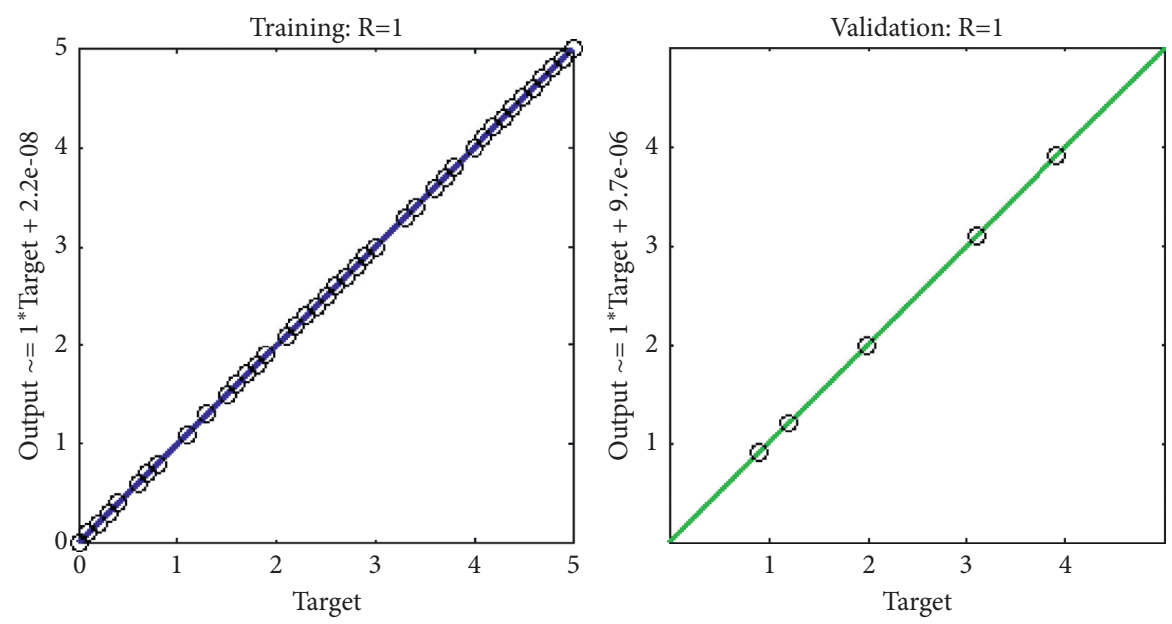

O Data
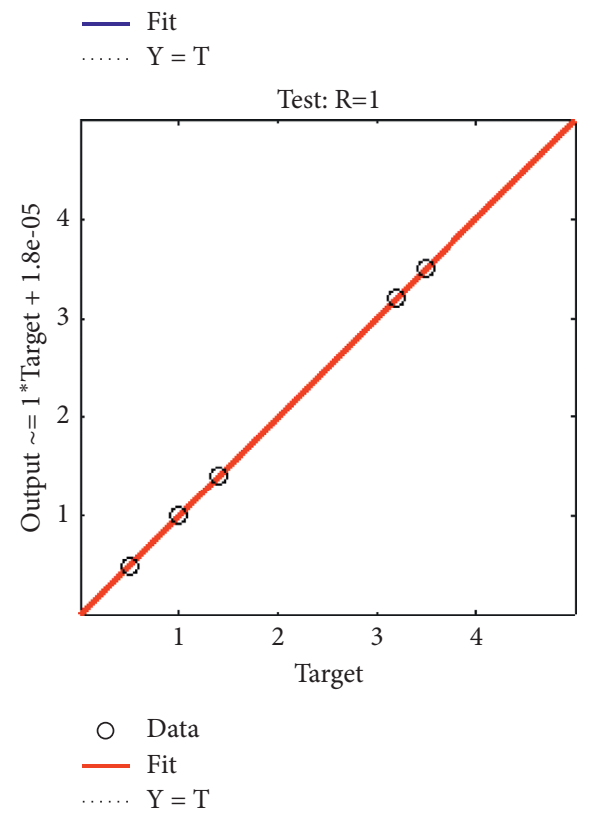

$$
\begin{array}{ll}
0 \quad \text { Data } \\
\text { Fit } \\
\ldots \ldots . . \quad \mathrm{Y}=\mathrm{T}
\end{array}
$$

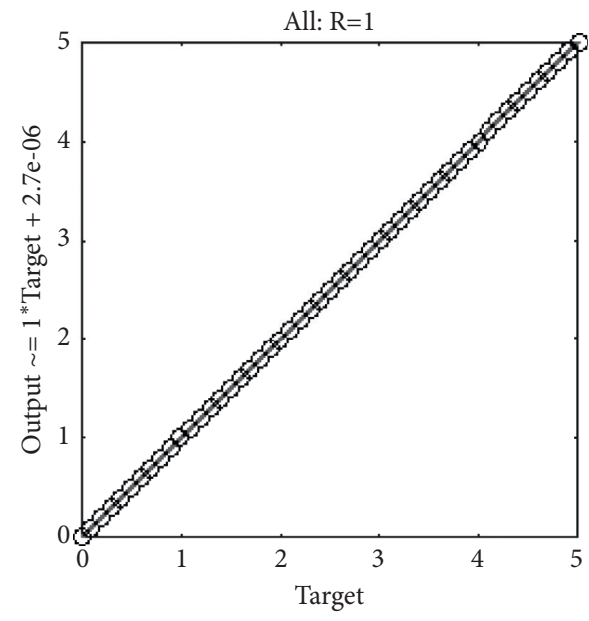

$$
\begin{array}{ll}
\mathrm{O} & \text { Data } \\
\text { - Fit } \\
\ldots . . . & \mathrm{Y}=\mathrm{T}
\end{array}
$$

FIgURE 15: Regression illustration of NN-BLMM results in case 2 of scenario 1 for FSE-HT.

(i) A new application based on artificial intelligencebased computing using neural network-based backpropagation with Levenberg-Marquardt is implemented for studying and solving the FSE-HT

(ii) The dataset of the NN-BLMM model is generated and produced for variations of Deborah and Prandtl parameters through the OHAM

(iii) The governing equations are transformed from a set of PDEs into ODEs by using a similarity transformation

(iv) The processing of the NN-BLMM means TR, TS, and VD of the FSE-HT model for different scenarios to obtain the approximate solution and comparison with reference results

(v) The convergence analysis based on the MSE, EH, and RG plots is employed to ensure the performance of NN-BLMM for the detailed analysis of the boundary layer flow model
The mathematical modeling of the FSE-HT is explained in Section 2. The analysis of FSE-HT is also given in Section 3. Section 4 presents the numerical results and graphical representations of the NN-BLMM model for the FSE-HT with more discussions and comparisons. Finally, Section 5 gives concluding remarks of the proposed study for the FSE-HT.

\section{Problem Formulation}

We consider two-dimensional laminar viscous flows over a semi-infinite flat plate under the boundary layer approximation as given in Figure 1. The governing equations are [28]

$$
\begin{gathered}
\frac{\partial u}{\partial x}+\frac{\partial v}{\partial y}=0 \\
u \frac{\partial u}{\partial x}+v \frac{\partial v}{\partial y}=U_{s} \frac{d U_{s}}{d x}+v \frac{\partial^{2} u}{\partial^{2} y}
\end{gathered}
$$



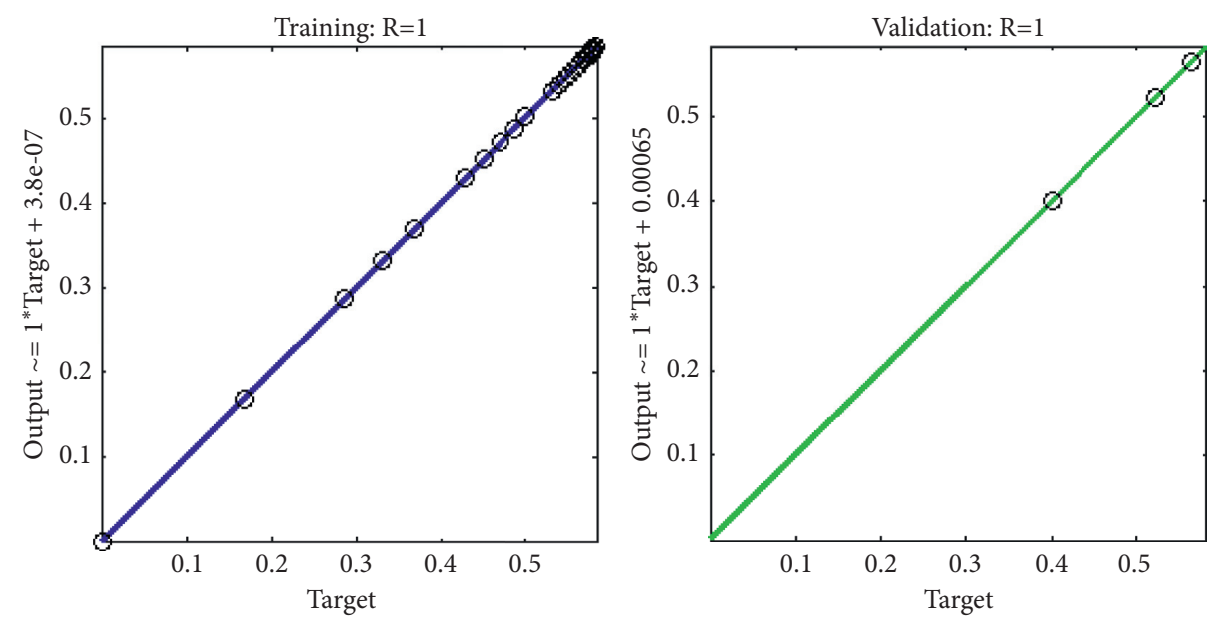

O Data
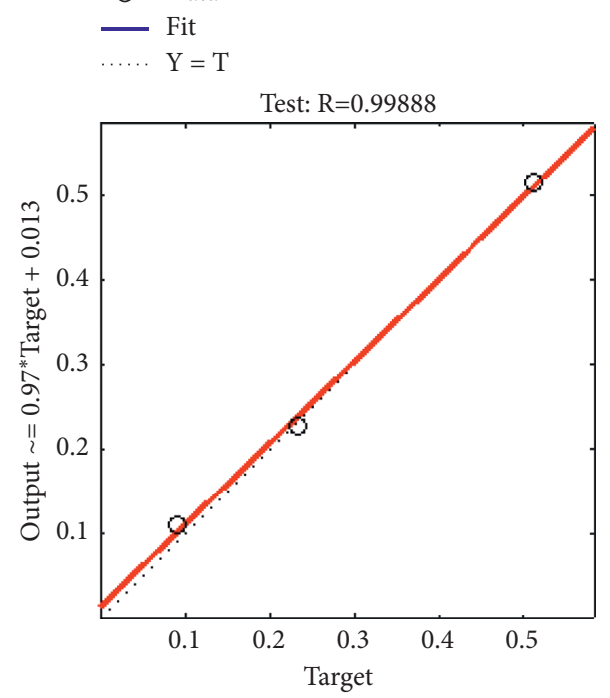

O Data

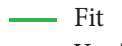

.... $\mathrm{Y}=\mathrm{T}$

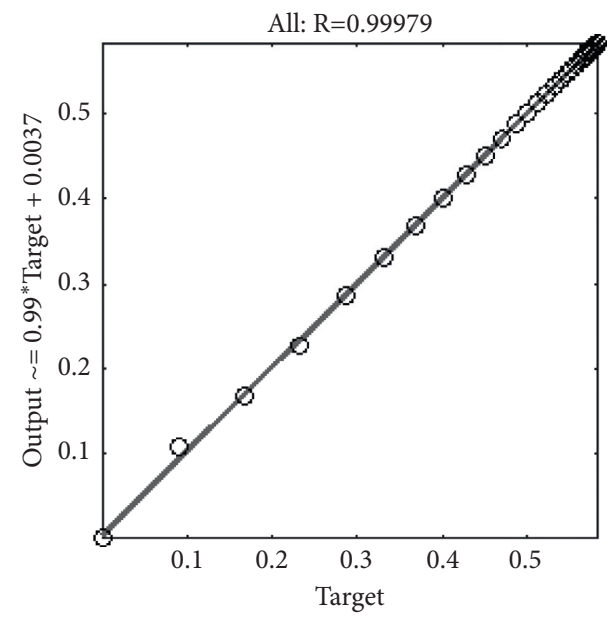

Data
- Fit
$\ldots \ldots$ Y.. Y $=\mathrm{T}$

O Data

Fit

… $\mathrm{Y}=\mathrm{T}$

FIgURE 16: Regression illustration of NN-BLMM results in case 3 of scenario 1 for FSE-HT.

$$
u \frac{\partial T}{\partial x}+v \frac{\partial T}{\partial y}=a \frac{\partial^{2} T}{\partial y^{2}}
$$

where $u$ and $v$ are velocity components in $x$ - and $y$-directions, $U_{s}(x)$ is the free stream velocity, " $a$ " is the thermal diffusivity, and $v$ is the kinematic viscosity.

In the two-dimensional case, the incompressible boundary layer flow over a wedge of angle $\beta \pi$ is shown in Figure 1. The free stream velocity of the form $U_{e}(x)=c x^{r}$ can be computed using the similarity transformation as follows:

$$
\begin{aligned}
u(x, y) & =U_{s} f^{\prime}(\xi), \\
\xi & =y \sqrt{\frac{(r+1) C}{2}} x^{(m-1) / 2}, \\
\theta(\xi) & =\frac{T-T_{\infty}}{T_{w}-T_{\infty}} .
\end{aligned}
$$

Using equation (4) in equations (1)-(3), the Falkner-Skan equation [28] can be calculated as

$$
\begin{array}{r}
f^{\prime \prime \prime}(\xi)+f(\xi) f^{\prime \prime}(\xi)+\beta\left(1-\left(f^{\prime}(\xi)\right)^{2}\right)=0, \\
\theta^{\prime \prime}(\xi)+\operatorname{Pr} f(\xi) \theta^{\prime}(\xi)=0,
\end{array}
$$

with boundary conditions

$$
\begin{aligned}
f(0) & =0, \\
f^{\prime}(0) & =0, \\
f^{\prime}(\infty) & =1, \\
\theta(0) & =1, \\
\theta(\infty) & =0,
\end{aligned}
$$

where Pr is the Prandtl number. 

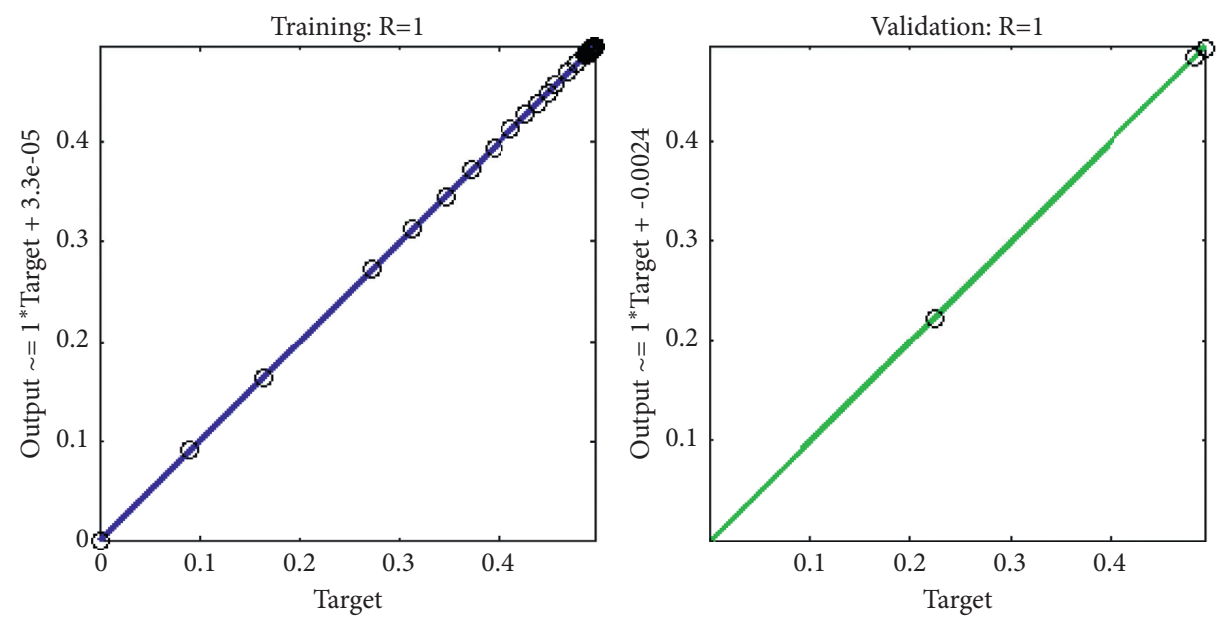

O Data

O Data

- Fit

$\mathrm{Y}=\mathrm{T}$
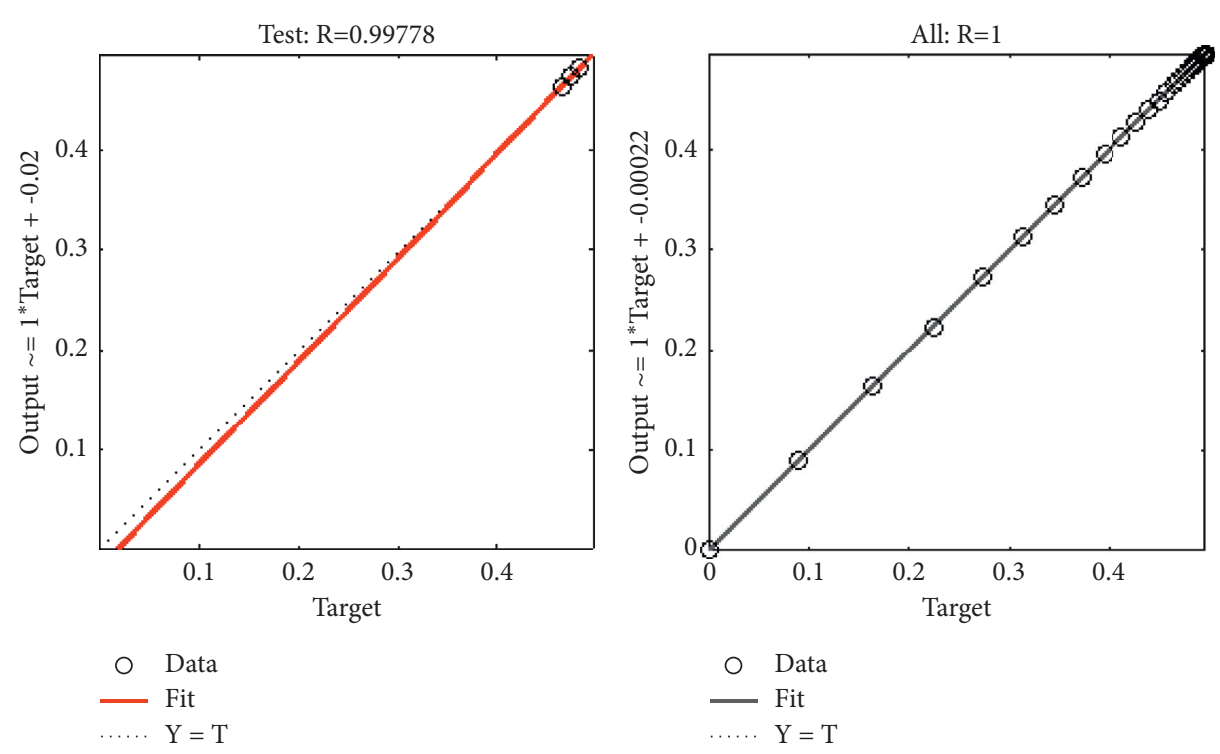

FIgURE 17: Regression illustration of NN-BLMM results in case 1 of scenario 2 for FSE-HT.

\section{Solution Procedure}

The solution procedure is performed by implementing the proposed NN-BLMM model using nftool in the MATLAB area. The structure of the NN-BLMM is given in Figure 2, and its data process is presented in Figure 3. Essentially, the NN-BLMM is used for three conditions with different parameters as set out in Table 1. The design of the NN-BLMM is based on ten numbers of neurons, as shown in Figure 4. A reference database of 201 input grids has been selected within the interval $[0,5] .80 \%$ of the data is used randomly in training, while $10 \%$ is used in the testing and validation process. Training data are used for the construction of a limited solution built on the MSE results. Verification data are used for demonstrating the behavior of the NN, whereas the test data are used for showing the performance of random inputs. Details about the scenarios and cases are given in Table 1.
The NN-BLMM-based computing paradigm with one hidden layer structure of neural networks is exposed in Figure 2.

The input data are operated in the single-layer neural network model with the help of the NN-BLMM to obtain the output result, as represented in Figure 3.

\section{Analysis of Results}

The workflow of the proposed NN-BLMM model for processing the FSE-HT is shown in Figure 4. Besides, the results of the NN-BLMM for cases 1-3 of all scenarios in working with $\mathrm{PF}$ and state are displayed in Figures 5 and 6, separately. The results of FT are shown in Figures 7-12. The EH results are given in Figure 13, whereas RA results are presented in Figures $14-19$ on three FSE-HT cases. Figure 5 shows the MSE for scenarios 1 and 2 at the best PF when the TR, VD, and TT data are run. Figure 6 shows the error gradient in the 

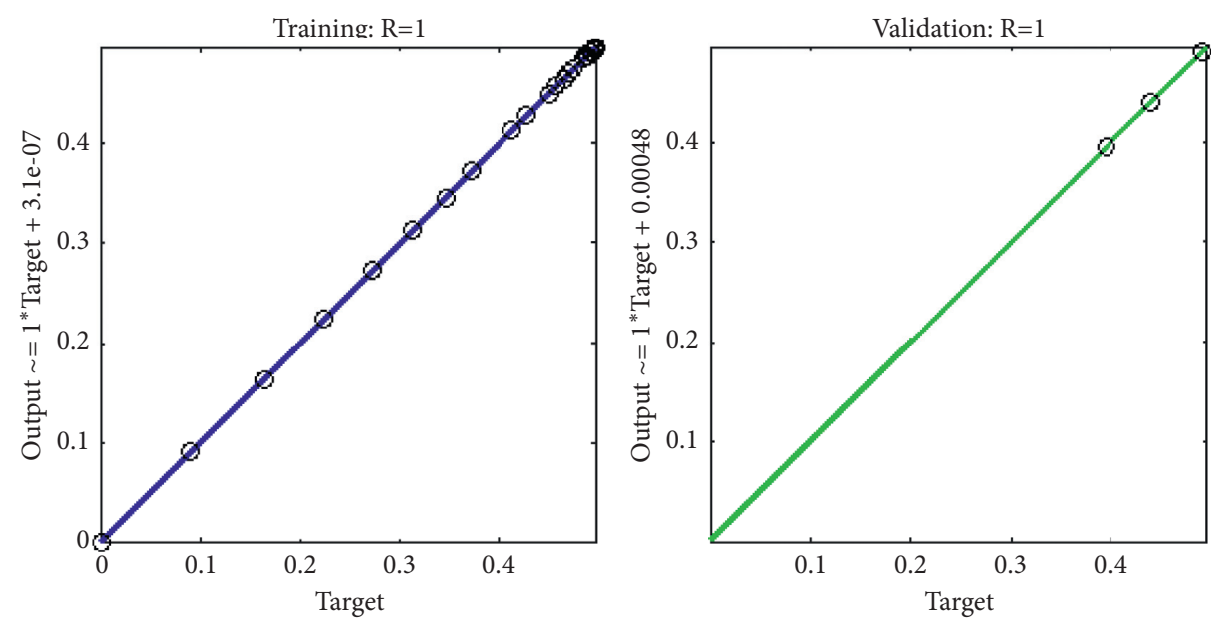

O Data

O Data

- Fit

…. $\mathrm{Y}=\mathrm{T}$
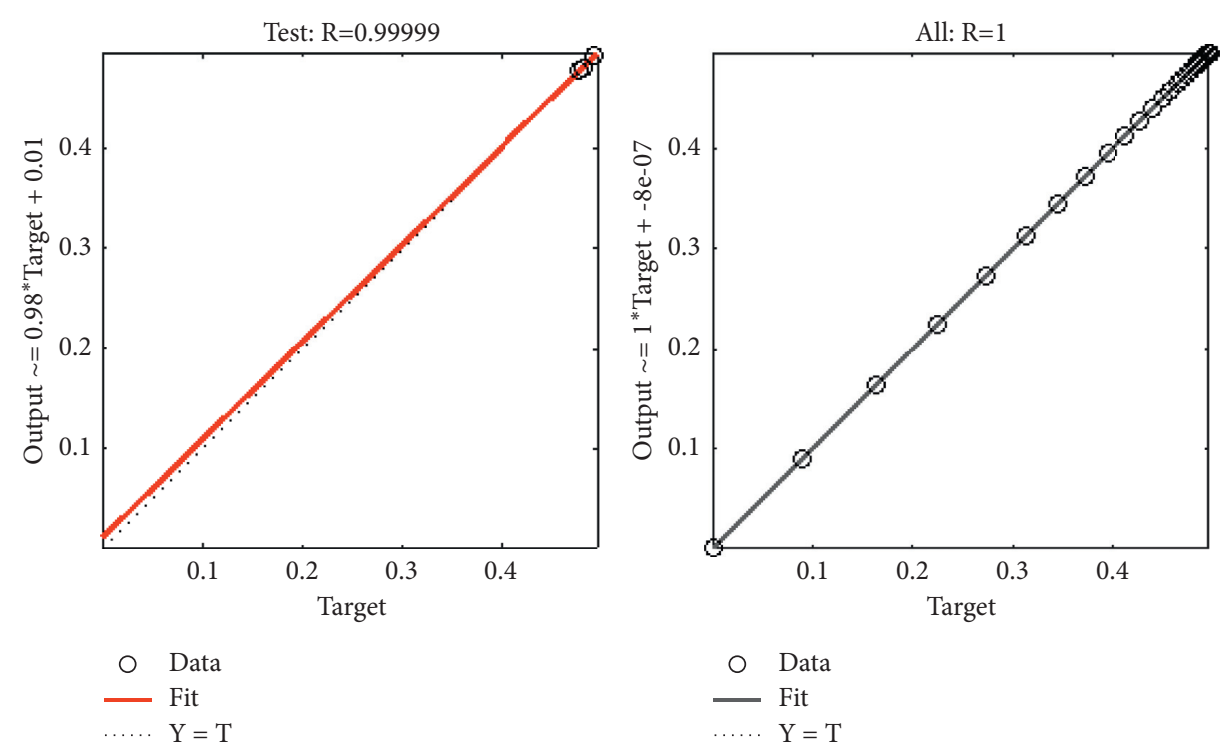

FIGURE 18: Regression illustration of NN-BLMM results in case 2 of scenario 2 of FSE-HT.

direction of magnitude calculated during the TR of the NNBLMM for all scenarios at each epoch, and its results are compare with numerical method results for valdiating the proposed method. The absolute errors are further explained with the help of Figures 7-13. The accuracy of the NNBLMM is verified by checking the results for the regression showing the accuracy of the NN-BLMM as given in Figures 14-19. In addition, the convergence control parameters in terms of executed epochs, MSE, PF, time of execution, and BP measures are presented in Table 2. In Figures 5(a)-5(f), MSE assembly of TR, VD, and TS procedures is presented for cases 1 and 3 of all scenarios (FSEHT). One can see that the best PF has been achieved at 224, $1000,366,72,143$, and 248 epochs with an MSE of about $2.4702 \times 10^{-8}, 1.3234 \times 10^{-10}, 1.2138 \times 10^{-8}, 2.7061 \times 10^{-5}$, $5.0276 \times 10^{-7}$, and $1.0658 \times 10^{-9}$, respectively. Appropriate values for GD and step Mu size of BP are $(9.9228 \times 10-08$, $1.0553 \times 10-07,9.9259 \times 10-08,9.6455 \times 10-8,8.4492 \times 10-$
7 , and $2.7359 \times 10-8)$ and $(10-08,10-8,10-08,10-08,10-09)$ as shown in Figures 6(a)-6(f). The results determine the correct and convergent PF of the NN-BLMM for each case. The maximum error achieved in the TS, PF, and VL by the proposed NN-BLMM is less than $0.1 \times 10-03,0.9 \times 10-05$, $0.1 \times 10-01,0.5 \times 10-03,3 \times 10-03$, and $0.3 \times 10-03$ as given in Figures 7-12. Error variability is also assessed with EH for every input point, and the results are given in Figures 13(a)13(f). The maximum error achieved is less than $-3.5 E-6$, $2.37 E-7,3.64 E-4,-1.1 E-4,-1.2 E-4$, and $2.56 E-6$ in all cases (FSE-HT). The investigation over RG is performed using the correlation studies. Moreover, the RG results are given in Figures 14-19, and the correlation $R$ values invariably revolve around unity of the NN-BLMM performance results for FSE-HT. Adopted cases are given in Table 2. The NN-BLMM performance is approximately $10_{-8}$ to $10_{-10}$ and $10_{-7}$ to $10_{-10}$ in cases 1 and 3 of all scenarios with 1-3 cases of FSE-HT. These results show 

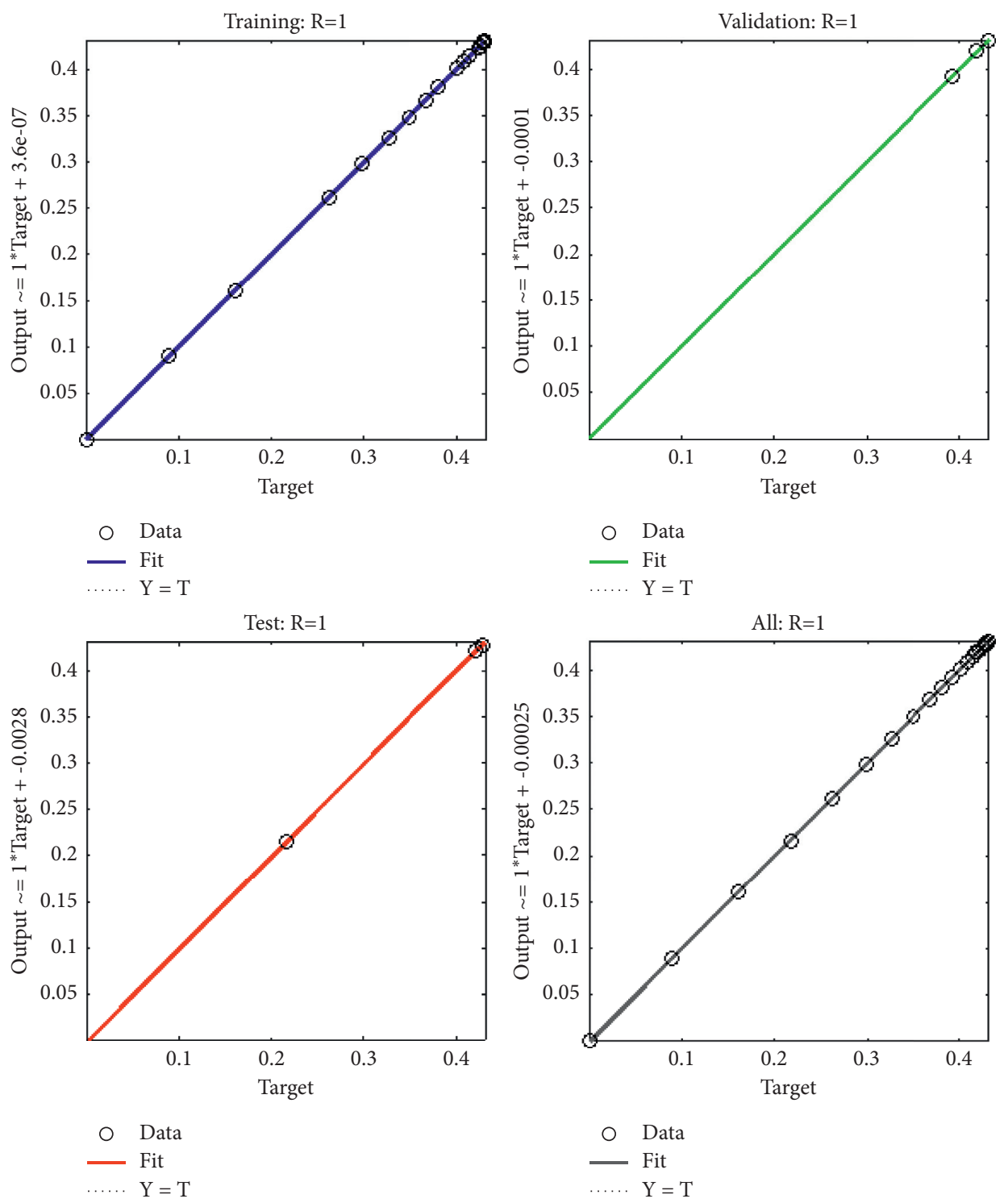

FIGURE 19: Regression illustration of NN-BLMM results in case 3 of scenario 2 for FSE-HT.

TABLE 2: The NN-BLMM results of scenarios 1-3 for FSE-HT.

\begin{tabular}{|c|c|c|c|c|c|c|c|c|}
\hline \multirow{2}{*}{ Scenario 1 cases } & \multicolumn{3}{|c|}{ Mean square error (MSE) } & \multirow{2}{*}{ Performance } & \multirow{2}{*}{ Gradient } & \multirow{2}{*}{$\mathrm{Mu}$} & \multirow{2}{*}{ Epoch } & \multirow{2}{*}{ Time } \\
\hline & Training & Validation & Testing & & & & & \\
\hline 1 & $7.77491 E-10$ & $6.78795 E-05$ & $1.51380 E-05$ & $7.70 \mathrm{E}-10$ & $7.61 E-06$ & $1.00 E-08$ & 504 & $<1$ \\
\hline 2 & $6.74192 E-09$ & $2.10370 E-05$ & $1.52281 E-07$ & $6.74 E-09$ & $1.26 E-05$ & $1.00 E-07$ & 1000 & $<1$ \\
\hline 3 & $5.21240 E-08$ & $3.20661 E-06$ & $1.71187 E-05$ & $4.85 E-08$ & $1.84 E-04$ & $1.00 E-07$ & 172 & $<1$ \\
\hline Scenario 2 cases & Training & $\begin{array}{l}\text { ean square err } \\
\text { Validation }\end{array}$ & Testing & Performance & Gradient & $\mathrm{Mu}$ & Epoch & Time \\
\hline 1 & $1.23663 E-07$ & $3.74133 E-07$ & $6.01470 E-05$ & $9.96 E-08$ & $2.55 E-05$ & $1.00 E-07$ & 28 & $<1$ \\
\hline 2 & $3.28408 E-10$ & $3.51972 E-08$ & $1.46030 E-09$ & $3.28 E-10$ & $9.95 E-08$ & $1.00 E-09$ & 934 & $<1$ \\
\hline 3 & $2.62694 E-10$ & $4.25158 E-08$ & $3.36674 E-07$ & $2.63 E-10$ & $5.88 E-07$ & $1.00 E-09$ & 1000 & $<1$ \\
\hline
\end{tabular}

the stability of PF for the NN-BLMM in each case of FSEHT equations. The velocity distribution along with the comparison with numerical results is plotted in Figures 20(a) and 21(a). The results of the NN-BLMM have been compared with RK-4 numerical solutions in each case, therefore, to achieve precision gauges, $\mathrm{AE}$ is determined from the reference solutions, and the results are shown in Figures 20(b) and 21(b) for case studies 1-3, respectively. 


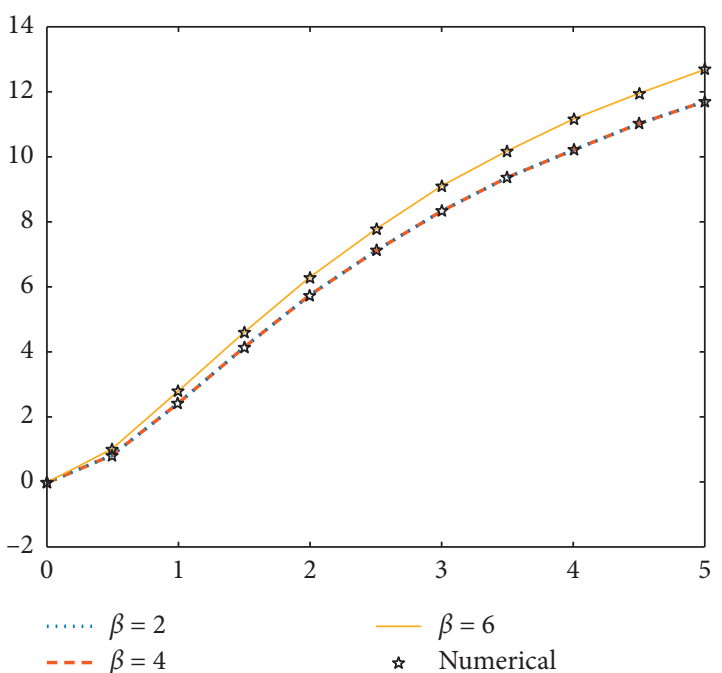

(a)

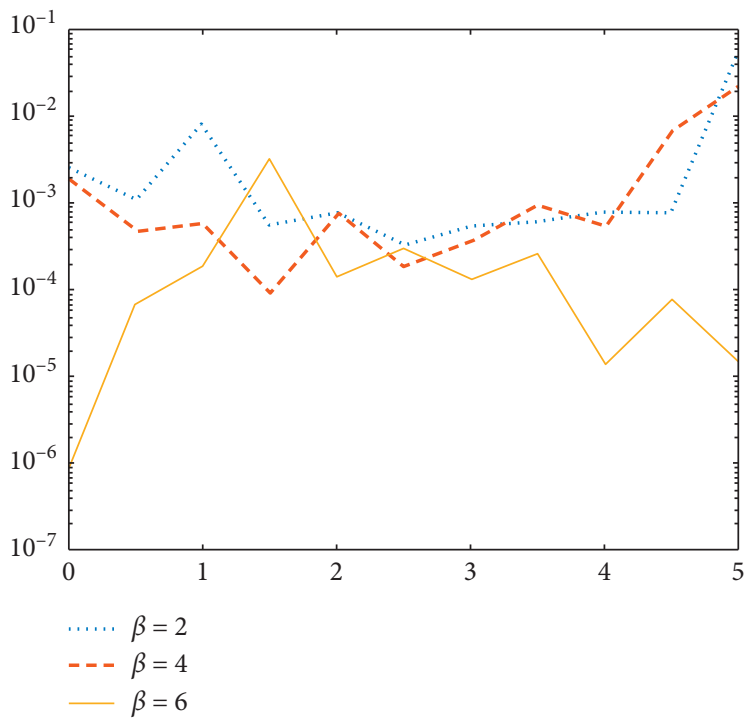

(b)

Figure 20: The results of the proposed NN-BLMM compared with reference results regarding scenario 1 of FSE-HT. (a) Variation of $\beta$. (b) Analysis of AE.

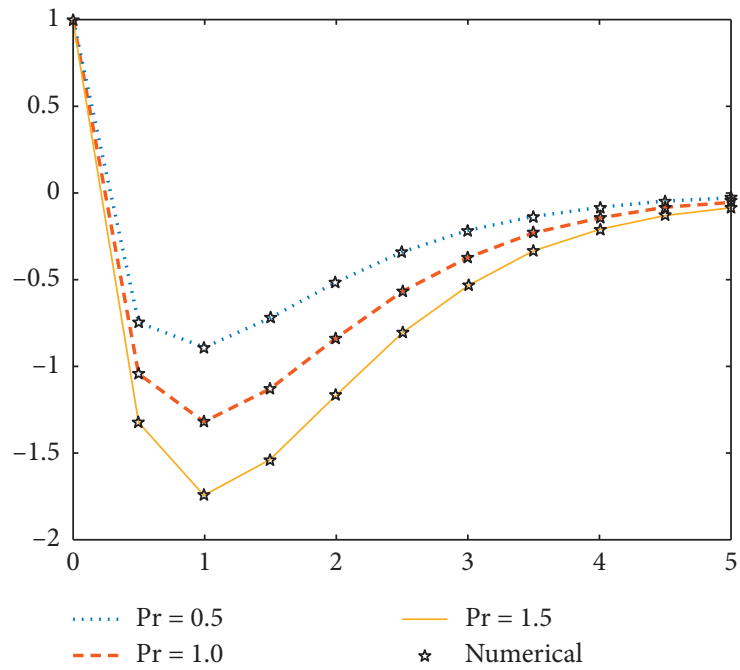

(a)

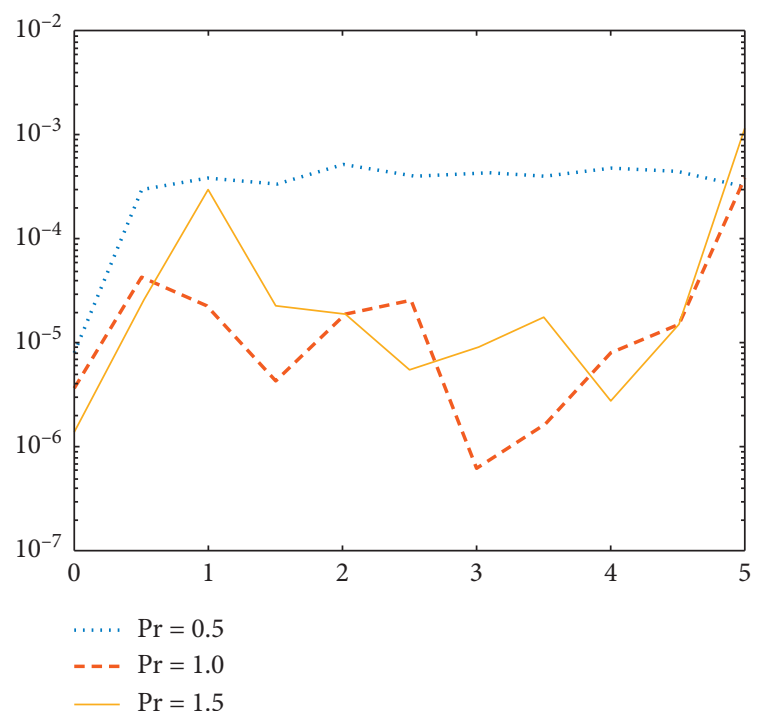

(b)

FIgURE 21: Comparison between the results of the NN-BLMM and reference results for scenario 2 of FSE-HT. (a) Pr variation. (b) Analysis of AE.

One can note that $\mathrm{AE}$ is almost $10-02$ to $10-04$ and $10-03$ to 10-06 in all scenarios, respectively. All of these numerical and graphical diagrams ensure the precise, flexible, and robust functionality of the NN-BLMM for FSE-HT. The nondimensional velocity profiles and temperature profiles are given in Figures 20(a) and 21(a), respectively. The variation of physical parameters $\beta$ and $\operatorname{Pr}$ is given in Figures 20(a) and 21(a), whereas the absolute error for each variation of $\beta$ and $\operatorname{Pr}$ is given in Figures 20(b) and 21(b). The solution obtained by the NN-BLMM is verified by the numerical method. It has been observed that an increase in the Deborah number makes an increase in the velocity profile and a decrease in the thermal boundary layer thickness. Similarly, by increasing the Prandtl number, the thermal boundary layer thickness is decreased. The results obtained by the NN-BLMM are compared with the results available in the literature which proves the accuracy and validation of the method as given in Table 3 . 
TABLE 3: The results of the initial slope $f^{\prime \prime}(0)$ achieved at different values of $\beta$.

\begin{tabular}{lcccccccc}
\hline$\beta$ & Hartree [17] & Asaithambi [22] & Asaithambi [23] & Salama [24] & $\begin{array}{c}\text { Zhang and } \\
\text { Chen [25] }\end{array}$ & $\begin{array}{c}\text { Rosales-Vera and } \\
\text { Valencia [26] }\end{array}$ & $\begin{array}{c}\text { OHAM } \\
{[28]}\end{array}$ & $\begin{array}{c}\text { Stochastic } \\
\text { method }\end{array}$ \\
\hline 2 & 1.687 & 1.687222 & 1.687218 & 1.687218 & 1.687218 & 1.687218 & 1.687218 & 1.687218 \\
1 & 1.233 & 1.23589 & 1.232588 & 1.232588 & 1.232587 & 1.232587 & 1.232587 & 1.232587 \\
0.5 & 0.927 & 0.927682 & 0.927680 & 0.927680 & 0.927680 & 0.927680 & 0.927680 & 0.927680 \\
-0.1 & 0.319 & 0.319270 & 0.319270 & 0.319270 & 0.319270 & 0.319270 & 0.319270 & 0.319270 \\
\hline
\end{tabular}

\section{Conclusions}

In this paper, we conclude that the NN-BLMM contains less computational work and does not require linearization. NN-BLMM is simply applicable. The NN-BLMM has better PF as compared to other numerical methods, and it minimizes the absolute error. Moreover, the NNBLMM is independent of the assumption of a small parameter, and it does not require the initial guess. The NN-BLMM converges faster when compared to other methods. The correctness of the NN-BLMM is authenticated by MSE, EH, RG, AE, FT, PF, TS, and TR. The NN-BLMM uses $80 \%, 10 \%$, and $10 \%$ of the reference data as TR, TS, and VL. By increasing the Deborah number, the velocity profile increases, whereas the thickness of the thermal boundary layer is decreased by increasing the Deborah number. The thickness of the thermal boundary layer is decreased by increasing the Prandtl number.

\section{Abbreviations}

$\beta$ : $\quad$ Deborah number

ANNs: Artificial neural networks

$v$ : $\quad$ Kinematic viscosity

NN: Neural network

BL: $\quad$ Boundary layer

$k$ : $\quad$ Thermal conductivity

Pr: $\quad$ Prandtl number

BVP: Boundary value problem

Eh: Epoch

MSE: Mean square error

$\rho: \quad$ Fluid density

$\mu$ : $\quad$ Dynamic viscosity

PF: Performance

TT: $\quad$ Testing

TR: $\quad$ Training

VD: Validation

EB: $\quad$ Error bin

EH: $\quad$ Error histogram

GD: Gradient

RG: Regression

AE: Absolute error

Ep: Epoch

MSE: Mean square error.

\section{Data Availability}

All the relevant data are included within the article.

\section{Conflicts of Interest}

The authors declare that there are no conflicts of interest regarding the publication of this research article.

\section{Acknowledgments}

This research was supported by the Researchers Supporting Project number (RSP-2021/244), King Saud University, Riyadh, Saudi Arabia.

\section{References}

[1] T. Alten, S. Oh, and H. Gegrl, Metal Forming Fundamentals and Applications, American Society of Metals, Geauga County, OH, USA, 1979.

[2] E. G. Fisher, Extrusion of Plastics, Wiley, New York, NY, USA, 1976.

[3] Z. Tadmor and I. Klein, Engineering Principles of Plasticating Extrusion, Polymer Science and Engineering Series, Van Nostrand Reinhold, New York, NY, USA, 1970.

[4] B. C. Sakiadis, "Boundary-layer behavior on continuous solid surfaces: I. Boundary-layer equations for two-dimensional and axisymmetric flow," AIChE Journal, vol. 7, no. 1, pp. 26-28, 1961.

[5] B. C. Sakiadis, "Boundary-layer behavior on continuous solid surfaces: II. The boundary layer on a continuous flat surface," AIChE Journal, vol. 7, no. 2, pp. 221-225, 1961.

[6] L. J. Crane, "Flow past a stretching plate," Zeitschrift für angewandte Mathematik und Physik ZAMP, vol. 21, no. 4, pp. 645-647, 1970.

[7] P. S. Gupta and A. S. Gupta, "Heat and mass transfer on a stretching sheet with suction or blowing," Canadian Journal of Chemical Engineering, vol. 55, no. 6, pp. 744-746, 1977.

[8] H. I. Anderson, "MHD flow of a viscoelastic fluid past a stretching surface," Acta Mechanica, vol. 95, pp. 227-230, 1992.

[9] P. D. Ariel, "MHD flow of a viscoelastic fluid past a stretching sheet with suction," Acta Mechanica, vol. 105, no. 1-4, pp. 49-56, 1994.

[10] C. Y. Wang, "The three-dimensional flow due to a stretching flat surface," Physics of Fluids, vol. 27, no. 8, pp. 1915-1917, 1984.

[11] J. F. Brady and A. Acrivos, "Steady flow in a channel or tube with an accelerating surface velocity. An exact solution to the Navier-Stokes equations with reverse flow," Journal of Fluid Mechanics, vol. 112, no. 1, pp. 127-150, 1981.

[12] C. Y. Wang, "Fluid flow due to a stretching cylinder," Physics of Fluids, vol. 31, no. 3, pp. 466-468, 1988.

[13] C. Y. Wang, "Liquid film on an unsteady stretching surface," Quarterly of Applied Mathematics, vol. 48, no. 4, pp. 601-610, 1990. 
[14] R. Usha and R. Sridharan, "The axisymmetric motion of a liquid film on an unsteady stretching surface," Journal of Fluids Engineering, vol. 117, no. 1, pp. 81-85, 1995.

[15] P. D. Ariel, "Computation of MHD flow due to moving boundary," Technical report MCS-2004-01, Department of Mathematical Sciences: Trinity Western University, Langley, Canada, 2004.

[16] P. D. Ariel, T. Hayat, and S. Asghar, "Homotopy perturbation method and axisymmetric flow over a stretching sheet," International Journal of Nonlinear Sciences and Numerical Stimulation, vol. 7, no. 4, pp. 399-406, 2006.

[17] D. R. Hartree, "On an equation occurring in Falkner-Skan's approximate treatment of the equations boundary layer," Proceedings of the Cambridge Philosophical Society, vol. 33, no. 2, pp. 233-239, 1921.

[18] A. M. O. Smith, "Improved solution of the Falkner-Skan equation boundary layer equation," Journal of the Aeronautical Sciences, vol. 10, 1954.

[19] T. Cebeci and H. B. Keller, "Shooting and parallel shooting methods for solving the Falkner-Skan boundary-layer equation," Journal of Computational Physics, vol. 7, no. 2, pp. 289-300, 1971.

[20] D. Meksyn, New Methods in Laminar Boundary Layer Theory, Pergamon Press, New York, NY, USA, 1961.

[21] A. Asaithambi, "Numerical solution of the Falkner-Skan equation using piecewise linear functions," Applied Mathematics and Computation, vol. 159, no. 1, pp. 267-273, 2004.

[22] A. Asaithambi, "A finite-difference method for the FalknerSkan equation," Applied Mathematics and Computation, vol. 92, no. 2-3, pp. 135-141, 1998.

[23] N. S. Asaithambi, "A numerical method for the solution of the Falkner-Skan Equation," Applied Mathematics and Computation, vol. 81, no. 2-3, pp. 259-264, 1997.

[24] A. A. Salama, "Higher-order method for solving free boundary-value problems," Numerical Heat Transfer, Part B: Fundamentals, vol. 45, no. 4, pp. 385-394, 2004.

[25] J. Zhang and B. Chen, "An iterative method for solving the Falkner-Skan equation," Applied Mathematics and Computation, vol. 210, no. 1, pp. 215-222, 2009.

[26] M. Rosales-Vera and A. Valencia, "Solutions of Falkner-Skan equation with heat transfer by Fourier series," International Communications in Heat and Mass Transfer, vol. 37, no. 7, pp. 761-765, 2010.

[27] S.-J. Liao, "A uniformly valid analytic solution of two-dimensional viscous flow over a semi-infinite flat plate," Journal of Fluid Mechanics, vol. 385, pp. 101-128, 1999.

[28] H. Ullah, S. Islam, M. Idrees, and M. Arif, "Solution of boundary layer flow with heat transfer by OHAM," Abstract and Applied Analysis, vol. 2013, Article ID 324869, 10 pages, 2013.

[29] M. Rosales and A. Valencia, "A note on solution of Blasius equation by Fourier series," Advances and Applications in Fluid Mechanics, vol. 6, no. 1, pp. 33-38, 2009.

[30] J. P. Boyd, "The Blasius function in the complex plane," Experimental Mathematics, vol. 8, no. 4, pp. 381-394, 1999.

[31] Z. Sabir, M. A. Z. Raja, M. Umar, and M. Shoaib, "Design of neuro-swarming-based heuristics to solve the third-order nonlinear multi-singular Emden-Fowler equation," The European Physical Journal Plus, vol. 135, no. 6, pp. 1-17, 2020.

[32] Z. Sabir, H. A. Wahab, M. Umar, M. G. Sakar, and M. A. Z. Raja, "Novel design of Morlet wavelet neural network for solving second order Lane-Emden equation," Mathematics and Computers in Simulation, vol. 172, pp. 1-14, 2020.
[33] A. Mehmood, A. Zameer, M. S. Aslam, and M. A. Raja, "Design of nature-inspired heuristic paradigm for systems in nonlinear electrical circuits," Neural Computing and Applications, vol. 32, no. 11, pp. 1-17, 2020.

[34] S. I. Ahmad, F. Faisal, M. Shoaib, and M. A. Z. Raja, "A new heuristic computational solver for nonlinear singular Thomas-Fermi system using evolutionary optimized cubic splines," The European Physical Journal Plus, vol. 135, no. 1, p. 55, 2020.

[35] S. Lodhi, M. A. Manzar, and M. A. Z. Raja, "Fractional neural network models for nonlinear Riccati systems," Neural Computing and Applications, vol. 31, no. 1, pp. 359-378, 2019.

[36] M. A. Z. Raja, M. A. Manzar, S. M. Shah, and Y. Chen, "Integrated intelligence of fractional neural networks and sequential quadratic programming for Bagley-Torvik systems arising in fluid mechanics," Journal of Computational and Nonlinear Dynamics, vol. 15, no. 5, 2020.

[37] Kh Hosseinzadeh, M. R. Mardani, S. Salehi, M. Paikar, M. Waqas, and D. D. Ganji, "Entropy generation of threedimensional Bödewadt flow of water and hexanol base fluid suspended by $\mathrm{Fe}_{3} \mathrm{O}_{4}$ and $\mathrm{MoS}_{2}$ hybrid nanoparticles," Pramana, vol. 95, no. 2.

[38] K. Hosseinzadeh, S. Roghani, A. R. Mogharrebi, A. Asadia, M. Waqasc, and D. D. Ganji, "Investigation of cross-fluid flow containing motile gyrotactic microorganisms and nanoparticles over a three-dimensional cylinder," Alexandria Engineering Journal, vol. 59, no. 5, pp. 3297-3307, 2020.

[39] K. Hosseinzadeh, S. Salehi, M. R. Mardani, F. Y. Mahmoudi, M. Waqas, and D. D. Ganji, "Investigation of nano-Bioconvective fluid motile microorganism and nanoparticle flow by considering MHD and thermal radiation," Informatics in Medicine Unlocked, vol. 21, Article ID 1000462, 2020.

[40] Y.-Q. Song, H. Waqas, K. Al-Khaled et al., "Bioconvection analysis for Sutterby nanofluid over an axially stretched cylinder with melting heat transfer and variable thermal features: a Marangoni and solutal model," Alexandria Engineering Journal, vol. 60, no. 5, pp. 4663-4675, 2021.

[41] K. Hosseinzadeh, S. Roghani, A. Mogharrebi, and D. D. Ganji, "Optimization of hybrid nanoparticles with mixture fluid flow in an octagonal porous medium by effect of radiation and magnetic field," Journal of Thermal Analysis and Calorimetry, vol. 143, no. 103, pp. 10-1007, 2021.

[42] K. Hosseinzadeh, A. Asadi, A. Mogharrebi, and D. D. Ganji, "Investigation of mixture fluid suspended by hybrid nanoparticles over vertical cylinder by considering shape factor effect," Journal of Thermal Analysis and Calorimetry, vol. 143, no. 19-20, 2021.

[43] M. Gholinia, K. Hosseinzadeh, and D. D. Ganji, "Investigation of different base fluids suspend by CNTs hybrid nanoparticle over a vertical circular cylinder with sinusoidal radius," Case Studies in Thermal Engineering, vol. 21, Article ID 100666, 2020.

[44] K. Hosseinzadeh, E. Montazer, M. B. Shafii, and D. D. Ganji, "Heat transfer hybrid nanofluid (1-butanol/ $\mathrm{MoS}_{2}-\mathrm{Fe}_{3} \mathrm{O}_{4}$ ) through a wavy porous cavity and its optimization," International Journal of Numerical Methods for Heat \& Fluid Flow, vol. 31, no. 5, pp. 1547-1567, 2021. 